\title{
FORMULATION AND EVALUATION OF AMOXICILLIN-TRIHYDRATE, METRONIDAZOLE AND FAMOTIDINE LOADED MUCOADHESIVE GASTRO-RETENTIVE FILMS
}

\author{
NIDHI JAIN SINGHAI ${ }^{1,2}$, RAHUL MAURYA ${ }^{2}$, SUMAN RAMTEKE ${ }^{2}$, SANJAY K. JAIN ${ }^{1}$
}

${ }^{1}$ Dr. Hari Singh Gour (A Central University), Sagar (MP), India, ${ }^{2}$ School of Pharmaceutical Sciences, R. G. P. V., Bhopal (MP), India Email: nidhinidhijn25@gmail.com

Received: 24 Apr 2019, Revised and Accepted: 04 Jul 2019

\begin{abstract}
Objective: To developed mucoadhesive gastro-retentive films of amoxicillin trihydrate, metronidazole and famotidine by using polymers and plasticizer for eradication of $H$. pylori infection.

Methods: The mucoadhesive gastro-retentive films of amoxicillin trihydrate, metronidazole and famotidine were prepared using solvent casting method. The optimized gastro-retentive films were characterized by using various parameters such as DSC, drug content uniformity, in vitro drug release, FTIR spectroscopy, SEM and ex-vivo drug permeation studies across the mucous membrane. The prepared mucoadhesive gastro-retentive films were evaluated with in vitro growth inhibition study and in vivo bacterial clearance study.

Results: The FTIR spectra indicated that there was no any interaction between the drugs and polymer. Drugs content was found to be in the range and there was no significant change in the surface morphology of the films after under storage. The bioadhesive property of prepared films exhibited highly bioadhesive property when increased the amount of chitosan and PAA (Polyacrylic Acid) used. We found that CH-PAA IPC (Chitosan-Polyacrylic Acid Inter-polymer Complex) films exhibited greater bioadhesion. The percent of growth inhibition by using each drug such as amoxicillin, metronidazole and famotidine was found to be $51.61 \%, 46.59 \%$ and $34.76 \%$, respectively whereas the combination of drugs were exhibited highest \% growth inhibition. The \% inhibition was found to be $81.00 \%$. The optimized formulation CH-PAA IPC (C1P2G2) and CH film (C1G2) showed highest growth inhibition of $H$. pylori bacteria. The growth inhibition was found to be $96.77 \%$ and $92.26 \%$, respectively. In vivo Bacterial Clearance Studies showed that the drugs loaded CH-PAA IPC film (C1P2G2) formulation exhibited better clearance from infection than CH film (C1G2) formulation and plain drugs solution at same doses. Drugs loaded CH-PAA IPC film formulation was found to be effective in the treatment of $H$. pylori infections effectively.
\end{abstract}

Conclusion: The developed gastro-retentive films of amoxicillin trihydrate, metronidazole and famotidine combination could be used for batter management of mucosal ulcer disease and eradication of $H$. pylori bacteria.

Keywords: Mucoadhesive, Gastro-retentive films, Amoxicillin trihydrate, Metronidazole, Famotidine, Solvent casting method

(C) 2019 The Authors. Published by Innovare Academic Sciences Pvt Ltd. This is an open access article under the CC BY license (http://creativecommons.org/licenses/by/4.0/) DOI: http://dx.doi.org/10.22159/ijap.2019v11i5.33729

\section{INTRODUCTION}

Helicobacter pylorus (H. pylori) is one of the most common pathogenic bacterial infections and it is found in the stomachs of approximately half of the world's population. It is the primary known cause of gastritis, gastroduodenal ulcer disease and gastric cancer. However, combined drug therapy as the general treatment in the clinic, the rise of antibiotic-resistant bacteria, adverse reactions and poor patient compliance are major obstacles to the eradication of $H$. pylori [1]. Although $H$. pylori has been shown to be highly sensitive to a single antimicrobial agent in many antibacterial in vitro trials, in clinical the eradication rate of $H$. pylori is still low [2]. There are three explanations for this finding: first, many antibiotics are unstable in the low $\mathrm{pH}$ of gastric acid; second, the concentration of the drug in the deep gastric mucus where the bacterium lives is too low and third, the amount of time that the antibiotic resides in the stomach is too short [3]. Gastroretentive dosage forms are one of the oral site-specific drug delivery systems that have been proposed. Gastroretentive drug delivery systems potentially prolong the gastric retention time and controlled/sustained release of a drug, thereby increasing the concentration of the drug at the application site, potentially improving its bioavailability and reducing the necessary dosage. Research into gastroretentive drug delivery systems has resulted in the development of several formulations such as floating systems, mucoadhesive/bioadhesive systems, expandablesystems and magnetic systems, all of which could prolong gastrointestinal (GI) residence time to improve drug effectiveness against $H$. pylori [4-6]. Triple therapies consisting of the combined use of antibiotics are frequently used in the clinical treatment of $H$. pylori associated with gastroduodenal disease. Therefore mucoadhesive gastroretentive films of amoxicillin trihydrate, metronidazole and famotidine were formulated by using polymers and plasticizer to combat the $H$. pylori bacteria.

\section{MATERIALS AND METHODS}

\section{Materials}

The drugs amoxicillin trihydrate, metronidazole and famotidine were provided as gift sample from Lapiz Pharma Sagar, Khandelwal laboratory Mumbai and Lupin research park Pune respectively. All other chemicals used were of analytical reagent grade.

\section{Methods}

Preparation of the chitosan-polyacrylic acid interpolymer complex (IPC) films

Chitosan solution was prepared by dispersing chitosan in $2 \%(\mathrm{v} / \mathrm{v})$ aqueous acetic acid solution and stirring overnight. Specified amount of amoxicillin trihydrate, metronidazole and famotidine were added to chitosan solution and stirred for $15 \mathrm{~min}$. PAA polymer was dissolved in distilled water and the $\mathrm{pH}$ of the solutions was adjusted by addition of $0.1 \mathrm{M} \mathrm{HCl}$ until the degree of ionization was less than $0.1 \%$ in order to avoid precipitation when mixing the solutions of the polymers, and obtain a homogenous mixture. The PAA suspension was drop wise added to the chitosan solution and mixed with a magnetic stirrer. Then, glycerol was added to it. Filmforming solutions were magnetically stirred for $3 \mathrm{~h}$. Cast onto a clean petri-dishes and dried at room temperature at $24 \mathrm{~h}$. dried films were conditioned in a desiccator containing a saturated solution of sodium bromide $(58 \% \mathrm{RH})$ at $25^{\circ} \mathrm{C}$ [7].

\section{Preparation of the chitosan (CH) films}

Chitosan solution was prepared by dispersing chitosan in $2 \%(\mathrm{v} / \mathrm{v})$ aqueous acetic acid solution and stirring overnight. Specified amount of amoxicillin trihydrate, metronidazole and famotidine were added to chitosan solution and stirred for 15 min with a 
magnetic stirrer. Then, glycerol was added to it. Film-forming solutions were magnetically stirred for $3 \mathrm{~h}$. Cast onto a clean petridishes and dried at room temperature at $24 \mathrm{~h}$. dried films were conditioned in a desiccator containing a saturated solution of sodium bromide $(58 \% \mathrm{RH})$ at $25^{\circ} \mathrm{C}$.

\section{Evaluation of mucoadhesive gastro-retentive film}

For evaluation of film weight three films of each formulation were taken and weighed individually. The experiments were carried out in triplicate and average values were reported.

\section{Thickness}

The film thickness was measured using micrometer screw gauge at three different places and the mean thicknesses of films were calculated.

\section{Folding endurance}

Folding Endurance of the films was determined by repeatedly folding one film at the same place till it broke or folding up to 300 times manually which was considered satisfactory to reveal good film property [8]. The number of times, the film could be folded at the same place without breaking gave the value of folding endurance. The mean values of three films were calculated.

\section{Mechanical properties}

Mechanical properties of the films were evaluated using TA. XT2 texture analyzer equipment equipped with a $5 \mathrm{~kg}$ load cell. Film strip in dimension of 50x10 mm and free from air bubbles or physical imperfections, were held between two clamps positioned at a distance of $3 \mathrm{~cm}$. A cardboard was attached on the surface of the clamp via a double-sided tape to prevent the film from being cut by the grooves of the clamp. During measurement, the top clamp at a rate of $2.0 \mathrm{~mm} / \mathrm{s}$ pulled the strips to a distance of $5 \mathrm{~cm}$ before returning to the starting point. The force was measured when the film broke. Result from film samples, which broke at and not between the clamps were not included in calculations. Measurements were run in three replicates for each film.

$$
\begin{aligned}
& \text { Tensile strength }(\mathrm{kg} / \mathrm{mm})^{2} \\
& =\frac{\text { Force at break }(\mathrm{kg})}{\text { Initial cross }- \text { sectional area of the sample }(\mathrm{mm})^{2}}
\end{aligned}
$$

\section{Percent swelling}

Films swelling properties were evaluated by determining the percentage of hydration. The hydration capacities of the film formulations were determined by weighing the film pieces before and after placing in agar plate. Each film was divided in portions of $1 \mathrm{~cm}^{2}(1 \mathrm{~cm} \times 1 \mathrm{~cm})$ and cut, weighed and allowed to swell on the surface of $2 \%$ agar plate kept in an incubator maintained at $37 \pm 0.2^{\circ} \mathrm{C}$. Increase in weight of the film ( $\mathrm{n}=3$ ) was determined at every $1 \mathrm{~h}$ interval for $6 \mathrm{~h}$.

$$
\text { Percent swelling }(\% \mathrm{~S})=\frac{X t-X 0}{X 0} \times 100
$$

Where, $X_{t}$ is the weight of the swollen film after time $t, X_{0}$ is the initial film weight at zero time.

\section{Percent moisture sorption}

The films $(2 \times 2 \mathrm{~cm}$ size $)$ of each formulation were dried and after drying, the weight of each film was measured. The films were successively transferred to desiccators over saturated salt solutions of sodium nitrite $(75 \pm 5 \% \mathrm{RH})$ at $25^{\circ} \mathrm{C}$. At regular intervals (up to 5 d), the film was removed from the desiccators and weighted and percent moisture sorption was calculated. The experiments were carried out in triplicate and average values were reported.

$$
\begin{aligned}
& \text { Moisture absorption } \\
& \text { Wt.of exposed film }- \text { Wt.of conditioned film } \\
& \text { Wt.of conditioned film }
\end{aligned} 100
$$

\section{Drug content uniformity}

Drug content uniformity was determined by dissolving the film $(2 \times 2 \mathrm{~cm}$ size) of each formulation by homogenization in $100 \mathrm{ml}$ of acetate buffer
(pH 5.0) for $8 \mathrm{~h}$ under occasional shaking. The $5 \mathrm{ml}$ solution was taken and diluted with acetate buffer (pH 5.0) up to $20 \mathrm{ml}$, and the resulting solution was filtered through a $0.45 \mathrm{~mm}$ whatman filter paper. The drug content was then determined after proper dilution at $228 \mathrm{~nm}, 320 \mathrm{~nm}$ and $266 \mathrm{~nm}$ using a UV-spectrophotometer. The experiments were carried out in triplicate and average values were reported.

\section{In vitro study}

In vitro drug release study is a prerequisite for evaluating the in vivo performance of a drug delivery system because the in vitro drug release profile provides the most sensitive and reliable information for in vivo evaluation that helps in ascertaining the future behavior of the designed formulation with regard to its drug release pattern and the time duration of its action in a biological system $[9,10]$.

\section{In vitro drug release study}

The USP six station dissolution apparatus type- 1 was used throughout the study. One film $(2 \times 2 \mathrm{~cm}$ size $)$ of each formulation was fixed to the central shaft using an acrylate adhesive. The dissolution medium was consisted of $900 \mathrm{ml}$ of $0.1 \mathrm{M} \mathrm{HCl}$ or simulated gastric fluid (SGF, pH 1.2). The release study was carried out at $37 \pm 0.5^{\circ} \mathrm{C}$ with a rotation speed of $50 \mathrm{rpm}$. The release study was performed for $8 \mathrm{~h}$. After every $1 \mathrm{~h}, 3 \mathrm{ml}$ samples was withdrawn from each station and immediately it was replaced with fresh media. The withdrawn samples were filtered; $2 \mathrm{ml}$ of the filtrate was diluted to $10 \mathrm{ml}$ using acetate buffer ( $\mathrm{pH} 5.0$ ). The samples were analyzed spectrophotometrically at $228 \mathrm{~nm}, 320 \mathrm{~nm}$ and $266 \mathrm{~nm}$.

\section{Kinetic of drug release}

The kinetic of drug release from the gastro retentive films were established using the formula given by peppas, used to study the drug release behavior from the polymeric drug delivery systems. The release kinetic parameters were calculated according to peppas equation [10].

$$
M t / M w=k t^{2}
$$

Where, $\mathrm{Mt} / \mathrm{Mw}$ is the fractional release of the drug, $\mathrm{t}$ denotes the release time, $\mathrm{k}$ represents a kinetic constant, incorporating structural and geometrical characteristics of the controlled release device, and $\mathrm{n}$ is the diffusional exponent and characterizes the type of release mechanism during the dissolution process.

\section{Ex vivo drug permeation studies}

\section{Preparation of excised goat stomach mucosa}

Goat stomach pouch was procured from the local slaughterhouse. The pouch was washed and rinsed with the normal saline to remove any loose material from the pouch a thin layer of mucosa of about 30 $\mathrm{mm}$ diameter was stripped out with the help of forceps. The mucosa was flattened, kept in normal saline at refrigerated temperature overnight.

\section{Modified diffusion cell}

For ex vivo drug permeation study, a modified diffusion cell was used. It considered of an open-ended glass cylinder of approx. $4 \mathrm{~cm}$ diameter and a beaker filled with $100 \mathrm{ml}$ PBS (pH 7.4). The excised mucosa was tied delicately on to one end of the glass cylinder. A 2.0 $\mathrm{cm}$ diameter film of each formulation under study was placed in intimate contact with the goat stomach mucosa. Teflon bead was placed in the receptor compartment filled with $100 \mathrm{ml}$ of PBS (pH 7.4). The cell contents were stirred with a magnetic stirrer and temperature of $37 \pm 1^{\circ} \mathrm{C}$ was maintained throughout the experiment.

\section{Surface morphology (SEM)}

Scanning electron microscope was used as a visualizing aid for surface morphology. The films were mounted on an aluminium sample support by means of a conductive and double-sided adhesive tape. The morphologies of the film surfaces and analyzed using a Philips XL30 TMP Scanning Electron Microscope (LEO 435 VP, Eindhoven Netherlands) at an acceleration voltage of $30 \mathrm{kV}$, and photomicrographs were taken at suitable magnification. The images were taken without the use of a metal coating. 


\section{Characterization of the polymer-polymer interaction}

DSC and IR spectroscopy were used for the examination of the interaction between the two oppositely charged polymers in the films.

\section{Differential scanning calorimetric studies}

DSC is a thermo analytical technique used to observe fusion and crystallization events as well as glass transition temperature $(\mathrm{Tg})$. Measurements were performed over the temperature range of 30$350^{\circ} \mathrm{C}$ at the heating rate of $5^{\circ} \mathrm{C} / \mathrm{min}$ in hermetically sealed aluminium pans.

\section{Fourier transformed infra red studies}

The FTIR spectra of homopolymers and polyion complex membranes were scanned using FTIR spectrometer Bruker IFS-55, Switzerland. (Perkin Elmer, 1600 Series, USA).

\section{Stability studies}

Formulations were stored in amber colour glass bottle at temperature $4.0 \pm 1^{\circ} \mathrm{C}, 15 \pm 1^{\circ} \mathrm{C}$ and $35 \pm 1^{\circ} \mathrm{C}$ for a period of $45 \mathrm{~d}$ and were observed for any change in surface morphology, folding endurance and surface $\mathrm{pH}$.

\section{Percent residual drugs content}

The selected film was kept at $4.0 \pm 1^{\circ} \mathrm{C}, 15 \pm 1^{\circ} \mathrm{C}$ and $35 \pm 1^{\circ} \mathrm{C}$ and drug content was determined by periodically withdrawing the film and processed for drug estimation.

\section{In vitro growth inhibition study}

Quantitation of in vitro antimicrobial activity of formulations was done in term of $\%$ growth inhibition. The method selected for proposed study was turbidometric based on optical density measurements $[11,12] .10 \mathrm{ml}$ suspension of $H$. pylori in brucella broth $\left(10^{9} \mathrm{CFU} / \mathrm{ml}\right)$ was taken in culture flasks; weights of Different group of formulations were calculated according to MIC of all three drugs (amoxicillin, metronidazole and famotidine) and added to it and the flasks were incubated in microaerophilic environment at $37^{\circ} \mathrm{C}$. The bacterial growth was monitored by optical density (OD) measurement using a Shimadzu 1601 $\mathrm{UV} /$ visible spectrophotometer at $660 \mathrm{~nm}$ against blank, that is, uninoculated, broth daily for up to $4 \mathrm{~d}$. Culture flasks containing placebo systems were also included in the study so as to detect any antimicrobial activity. The percent growth inhibition was determined using the formula:

$\%$ Growth inhibition $=\frac{O . D . \text { of control at particular time interval }-O . D . \text { of sample at the same time interval }}{O . D \text {. of control at a particular time interval }}$

Where, control refers to $H$. pylori broth and sample refers to $H$. pylori broth incubated with formulations.

\section{In vivo bacterial clearance study}

Healthy, disease free male Balb/c mice (weight 25-35 g and age 6-8 w) were procured from the animal house of I. T. R. C., Lucknow (U. P.) India. All the animal study protocols (Reference no. 09/DB/177(1)) were duly approved by the Institutional Animal Ethics Committee of Dr. H. S. Gour University, Sagar (M. P.), India and the studies were carried out in accordance with the Council for Purpose and Supervision of Experiment on Animals (CPCSEA), Ministry of Social Justice and Empowerment Govt. of India. The mice were kept with proper maintenance of temperature $\left(25^{\circ} \mathrm{C}\right)$, relative humidity (55\%), and light/dark cycle $(12 \mathrm{~h} / 12 \mathrm{~h})$. They were provided appropriate feed and continuous water supply of fresh water.

\section{Preparation of pathogenic $H$. pylori culture}

Gastric biopsy specimens were taken from patients with gastritis, gastric and duodenal ulcer through the gastroduodenoscope. The procedure was done in GIT endoscope unit at S. G. P. G. I. M. S.
Lucknow. The method used for in vivo study of $H$. pylori infection is known as Qian's method.

\section{Inoculation of $\boldsymbol{H}$. pylori and administration of formulations to rat}

All 6-8 w old Male Sprague Dawley rats were fasted overnight before inoculation prior to euthanasia. The animals were divided into four groups, each group consisting of 6 rats and each animal kept separately under laboratory condition. They had free access to commercial pellet diet and ad libitum. $1 \mathrm{ml}$ of broth containing about 10[10] colony forming units (CFUs) of $H$. pylori per $\mathrm{ml}$ was inoculated into the stomach of each rat via a gastric canula. Bacterial colonization was assessed four weeks post inoculation in a given rats by bacterial culture and histology of stomach tissue.

Group I was used as control and received physiological saline, group II received plain drug solution. Group III and IV received drugs loaded $\mathrm{CH}$ and drugs loaded CH-PAA IPC respectively. Formulations were given to each group once daily for three days. One day after administration of the final dose, the rats were sacrified, their stomachs removed and subjected to the following tests.

\section{Histopathological examination of rat stomach}

Histopathological examination was done for stomach specimens reserved in $10 \%$ formalin which were ranked according to the intensity of $H$. pylori colonization as follow: severe infection, moderate infection, mild infection and free from infection.

\section{Clearance of $H$. pylori from rat stomach}

Each stomach was homogenized with brucella broth ( $3 \mathrm{ml} / \mathrm{stomach}$ ) from which serial dilutions were plated on brucella chocolate agar medium (Difco). The plates were incubated at $37^{\circ} \mathrm{C}$ in microaerophilic environment in candle jar for 3-4 d. The viable cell count for each gastric wall was calculated by counting the no. of colonies on the agar plates. The logarithm of CFUs per gastric wall was expressed as \% bacterial recovery. The clearance rate (\%) was also calculated by the no. of rat cleared from infection per total no. of rat used in each group.

\section{Statistical analysis}

The results were expressed as mean (standard deviation (SD). Differences between the control and drug loaded formulation treated groups in bacterial colony count in the gastric wall were statistically analyzed by ANOVA, followed by Dunnet's multiple comparison test, as post-test $(n=5)$. Statistical significant differences between groups were defined as $\mathrm{P}<0.05$. Calculations were performed with the Graph Pad Instat software program (Graph Pad Software Inc., San Diego, CA)

\section{RESULTS AND DISCUSSION}

The attempts to develop gastro-retentive drug delivery systems may be largely divided into two classes: those that rely on the natural physiology of the gastrointestinal tract and those that are designed to overcome it. Approaches such as size or floatation, which rely on delayed emptying from the stomach, depend on the normal physiological duration of the fed state of 4-8 hr, following a meal and rather reproducible transit time through the small intestine [13, 14]. Mucoadhesive drug delivery systems are a dosage form that can stick to the mucosal surface by different mechanisms. This formulation involves a mucous coating or an adhesive polymer and is considered to be a bioadhesive form [15, 16]. The electronic theory, adsorption theory, wetting theory and diffusion theory are invoked to explain the adhesive mechanisms $[16,17]$.

The mucoadhesive gastro retentive films bearing amoxicillin trihydrate, metronidazole and famotidine were prepared using solvent casting method. This method provides good drug content uniformity. The effects of glycerol percentage on the basis of film weight, thickness, folding endurance and tensile strength are reported in (table 1). 
Table 1: Composition and evaluation report of CH-PAA IPC and $\mathrm{CH}$ prepared gastroretentive (GR) films

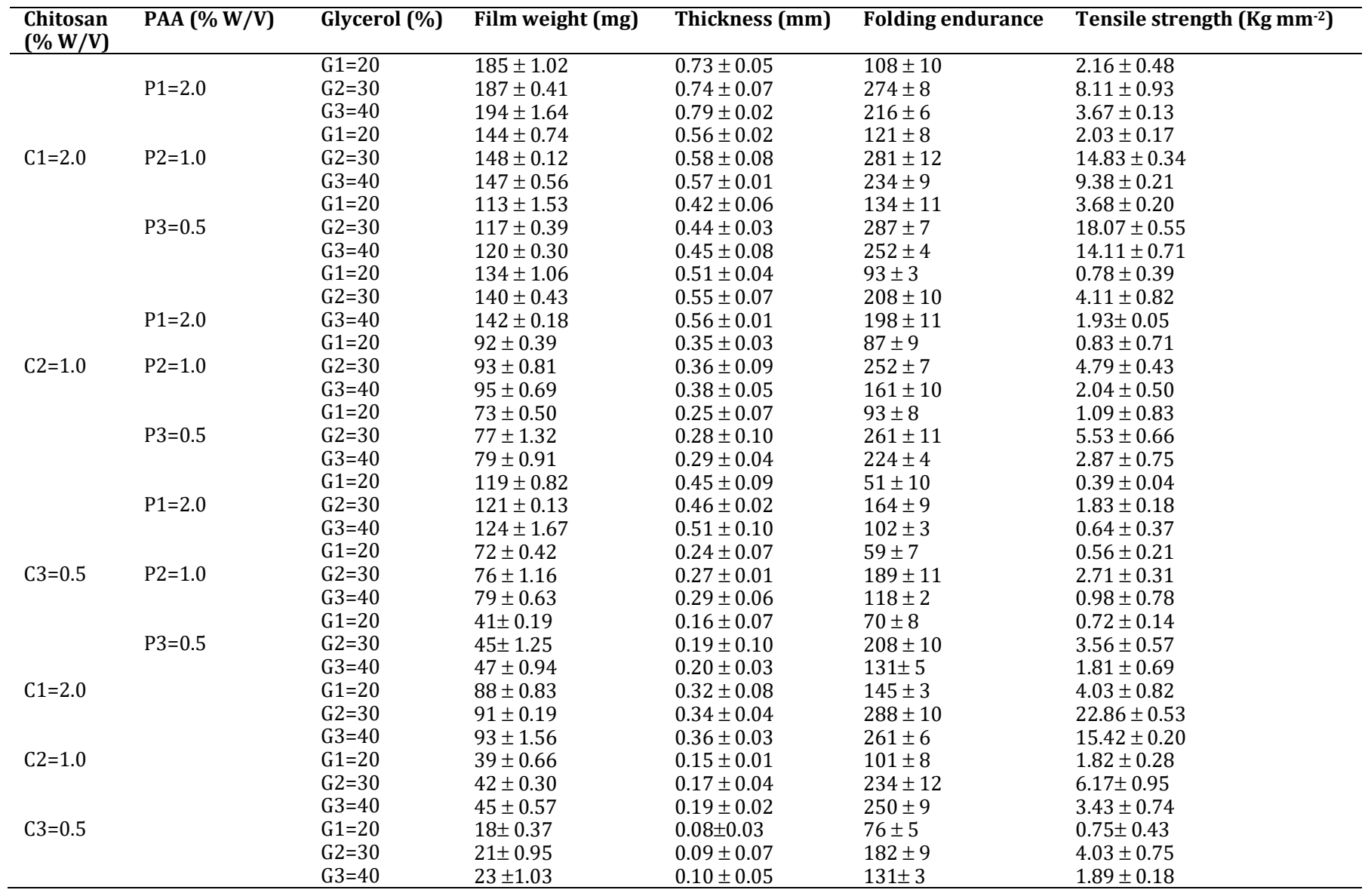

The percentage $(\%)$ of plasticizer is given in relation to the total dry weight of the polymers. $N=3 ; \pm \mathrm{SD}$

On the basis of film weight, thickness, folding endurance and tensile strength, $3 \%$ glycerol plasticizer was optimized. These optimized GR films were characterized for various attributions. The folding endurance values range from $51 \pm 10$ to $145 \pm 3$ and tensile strength values range from $0.39 \pm 0.54$ to $4.03 \pm 0.82$ and are referred to films C3P1G1 and C1G1, respectively. The folding endurance values range from $288 \pm 10$ to $164 \pm 9$ and tensile strength values range from $22.86 \pm 0.53$ to $1.83 \pm 0.18$ and are referred to films C1G2 and C3P1G2 respectively. It indicates that filmC1G2 is better in term of flexibility. The folding endurance values range from $261 \pm 6$ to $102 \pm 3$ and tensile strength values range from $15.42 \pm 0.20$ to $0.64 \pm 0.37$ and are referred to films C1G3 and C3P1G3 respectively. It is observed that as on increasing the percent plasticizer (glycerol) 20 to $40 \%$ in the polymer matrix, the film weight was found to increase from $18 \pm 0.37$ to $23 \pm 1.03 \mathrm{mg}$, respectively and its marginal increase in thickness was observed that is $0.08 \pm 0.03$ to $0.10 \pm 0.07 \mathrm{~mm}$, respectively in case of plain chitosan films $(0.5 \% \mathrm{w} / \mathrm{v})$ while it was $185 \pm 1.02$ to $194 \pm 1.64 \mathrm{mg}$ in weight and $0.73 \pm 0.05$ to $0.79 \pm 0.07 \mathrm{~mm}$ thickness in case of chitosan and PAA polymer matrix.

The folding endurance and tensile strength values of films increased with increased concentration of chitosan and decreased concentration of PAA. Tensile strength is related to the elastic and brittle character of the film. Glycerol improves both flexibility and resistance, with a maximum effect at 30\%. Glycerol reduces the rigidity of the bulk polymer network, originating films with increased polymer chain movements (increases folding endurance and tensile strength). $30 \%$ of glycerol was then selected to precede the study.

Appropriate swelling behavior of a gastro retentive adhesive system is the essential property for uniform and prolonged release of the drug and affective mucoadhesion.

Table 2: Swelling percentage of different GR films

\begin{tabular}{|c|c|c|c|c|c|c|c|c|c|c|c|c|}
\hline \multirow{2}{*}{$\begin{array}{l}\text { Time } \\
\text { (h) }\end{array}$} & \multicolumn{12}{|c|}{ \% Swelling } \\
\hline & C1P1G2 & C1P2G2 & C1P3G2 & C2P1G2 & C2P2G2 & C2P3G2 & C3P1G2 & C3P2G2 & C3P3G2 & C1G2 & C2G2 & C3G2 \\
\hline \multirow[t]{2}{*}{1} & $43.08 \pm 3.1$ & $48.36 \pm 1$ & $41.01 \pm 1$ & $27.22 \pm 2$ & $31.13 \pm 1$ & $30.71 \pm 2$ & $28.28 \pm 0$ & $26.97 \pm 0$ & $8.37 \pm 0.2$ & 33.17 & 31.49 & $28.11 \pm 2$. \\
\hline & 2 & .58 & .82 & .95 & 03 & .63 & .72 & .49 & 9 & \pm 0.28 & \pm 3.49 & 12 \\
\hline \multirow[t]{2}{*}{2} & $54.23 \pm 0.6$ & $55.03 \pm 2$ & $49.32 \pm 1$ & $37.63 \pm 1$ & $41.61 \pm 2$ & $37.69 \pm 3$ & $35.52 \pm 0$ & $33.19 \pm 0$ & $11.73 \pm 0$ & 38.63 & 35.28 & $32.85 \pm 1$. \\
\hline & 3 & .57 & .51 & .92 & 29 & .16 & .60 & .77 & 82 & \pm 1.32 & \pm 1.83 & 28 \\
\hline \multirow[t]{2}{*}{3} & $60.68 \pm 0.4$ & $63.52 \pm 2$ & $58.15 \pm 2$ & $43.17 \pm 2$ & $48.33 \pm 1$ & $46.83 \pm 2$ & $41.31 \pm 0$ & $38.34 \pm 1$ & $14.84 \pm 0$ & 47.51 & 42.39 & $39.40 \pm 2$. \\
\hline & 4 & .78 & .69 & .06 & 83 & .94 & .51 & .03 & 16 & \pm 2.59 & \pm 0.48 & 06 \\
\hline \multirow[t]{2}{*}{4} & $66.43 \pm 2.3$ & $68.13 \pm 2$ & $63.42 \pm 0$ & $46.34 \pm 3$ & $51.17 \pm 2$ & $52.41 \pm 3$ & $46.81 \pm 0$ & $43.81 \pm 0$ & $17.63 \pm 0$. & 53.48 & 49.03 & $44.08 \pm 1$. \\
\hline & 0 & .29 & .37 & .10 & 35 & .02 & .19 & .41 & 94 & \pm 1.37 & \pm 1.71 & 88 \\
\hline \multirow[t]{2}{*}{5} & $72.34 \pm 0.6$ & $76.47 \pm 1$ & $69.23 \pm 2$ & $52.08 \pm 0$ & $57.02 \pm 0$. & $57.56 \pm 2$ & $52.17 \pm 1$ & $50.37 \pm 0$ & $20.16 \pm 0$ & 59.32 & 55.73 & $51.94 \pm 1$ \\
\hline & 6 & .34 & .62 & .81 & 16 & .70 & .21 & .86 & 38 & \pm 1.79 & \pm 2.05 & 02 \\
\hline \multirow[t]{2}{*}{6} & $79.73 \pm 1.2$ & $82.21 \pm 2$ & $77.14 \pm 3$ & $58.14 \pm 3$ & $61.49 \pm 4$ & $64.03 \pm 2$ & $60.52 \pm 0$ & $58.92 \pm 1$ & $54.55 \pm 0$ & 65.60 & 62.14 & $57.37 \pm 1$ \\
\hline & 5 & .41 & .02 & .83 & 52 & .07 & .98 & .83 & 76 & \pm 4.19 & \pm 2.76 & 54 \\
\hline
\end{tabular}


Percent swelling was found to be high for C1P2G2 film (82.21 $\pm 2.41 \%$ ), due to regular porous nature of the PIC and a stronger electrostatic interaction between both polymeric chains would facilitate a better matrix-solvent interaction, allowing an efficient and rapid swelling and low for C3G2 film $(24.55 \pm 0.76 \%)$ due to a greater number of bonds in the network structure that also retard the drugs diffusion. Percent swelling was found to be slightly lower for C1P1G2 film $(79.73 \pm 1.25 \%)$ than C1P2G2 film $(82.21 \pm 2.41 \%)$, owing to the fact that this film was less porous and the existence of a higher amount of PAA and chitosan chains within the interpolymer complex obstructed the uptake of solvent in the network.

The water sorption in hydrophilic polymers is usually a non-linear process. Chitosan and PAA are hydrophilic polymers that are able to retain a considerable amount of water. In chitosan we can find at least three main sites for water absorption: hydroxyl groups, the amino group and the polymer chain end (a hydroxyl or an aldehyde group). Water absorption capacity of IPC was lower than chitosan.

Percent water sorption was found to be high for C1G2 film (13.11 $\pm 1.39 \%)$, and low for C3P1G2 film $(7.31 \pm 0.71 \%)$. Water absorption capacity of films increased with increasing concentration of chitosan and decreasing concentration of PAA. A bioadhesive property of films increases with increasing the chitosan concentration and concentration of PAA. Chitosan-PAA IPC films exhibited greater bioadhesion.

The in vitro residence time of the film C1P1G2 to C3G2 on the mucosal membrane was observed and it was noted that formulation C1P1G2 film remained on the mucosal membrane for more time $(8.52 \pm 0.36 \mathrm{~h})$ as compared to other formulations. It could be due to the presence of maximum concentration of chitosan and PAA (2:2).

Table 3: Percent moisture sorption of different GR films

\begin{tabular}{|c|c|c|c|c|c|c|c|c|c|c|c|c|}
\hline \multirow{2}{*}{$\begin{array}{l}\text { Time } \\
\text { (Day) }\end{array}$} & \multicolumn{12}{|c|}{ \% Moisture sorption } \\
\hline & $\begin{array}{l}\text { C1P1G } \\
2\end{array}$ & $\begin{array}{l}\text { C1P2 } \\
\text { G2 }\end{array}$ & $\begin{array}{l}\text { C1P3 } \\
\text { G2 }\end{array}$ & $\begin{array}{l}\text { C2P1 } \\
\text { G2 }\end{array}$ & $\begin{array}{l}\text { C2P2 } \\
\text { G2 }\end{array}$ & $\begin{array}{l}\text { C2P3 } \\
\text { G2 }\end{array}$ & $\begin{array}{l}\text { C3P1 } \\
\text { G2 }\end{array}$ & $\begin{array}{l}\text { C3P2 } \\
\text { G2 }\end{array}$ & $\begin{array}{l}\text { C3P3 } \\
\text { G2 }\end{array}$ & C1G2 & C2G2 & C3G2 \\
\hline 1 & $\begin{array}{l}7.03 \pm 0 . \\
18\end{array}$ & $\begin{array}{l}7.32 \pm 0.9 \\
2\end{array}$ & $\begin{array}{l}7.94 \pm 0.2 \\
5\end{array}$ & $\begin{array}{l}5.82 \pm 0 . \\
69\end{array}$ & $\begin{array}{l}6.14 \pm 0.5 \\
0\end{array}$ & $\begin{array}{l}6.65 \pm 0.9 \\
8\end{array}$ & $\begin{array}{l}4.83 \pm 0 . \\
12\end{array}$ & $\begin{array}{l}5.12 \pm 0 . \\
35\end{array}$ & $\begin{array}{l}5.46 \pm 0 . \\
22\end{array}$ & $\begin{array}{l}8.69 \pm 0.9 \\
2\end{array}$ & $\begin{array}{l}6.97 \pm 0.8 \\
1\end{array}$ & $\begin{array}{l}5.64 \pm 0 . \\
16\end{array}$ \\
\hline 3 & $\begin{array}{l}9.29 \pm 0 . \\
72\end{array}$ & $\begin{array}{l}9.18 \pm 0.1 \\
6\end{array}$ & $\begin{array}{l}9.63 \pm 0.2 \\
2\end{array}$ & $\begin{array}{l}7.14 \pm 0 . \\
38\end{array}$ & $\begin{array}{l}8.05 \pm 0.2 \\
0\end{array}$ & $\begin{array}{l}8.38 \pm 0.1 \\
6\end{array}$ & $\begin{array}{l}6.17 \pm 0 . \\
46\end{array}$ & $\begin{array}{l}6.55 \pm 0 . \\
61\end{array}$ & $\begin{array}{l}6.85 \pm 0 . \\
19\end{array}$ & $\begin{array}{l}10.43 \pm 0 . \\
10\end{array}$ & $\begin{array}{l}8.87 \pm 0.3 \\
3\end{array}$ & $\begin{array}{l}6.99 \pm 0 . \\
47\end{array}$ \\
\hline 5 & $\begin{array}{l}11.62 \pm 0 \\
.55\end{array}$ & $\begin{array}{l}11.90 \pm 1 \\
28\end{array}$ & $\begin{array}{l}12.71 \pm 0 \\
87\end{array}$ & $\begin{array}{l}9.53 \pm 0 . \\
41\end{array}$ & $\begin{array}{l}10.18 \pm 1 \\
82\end{array}$ & $\begin{array}{l}10.89 \pm 0 . \\
49\end{array}$ & $\begin{array}{l}7.31 \pm 0 . \\
71\end{array}$ & $\begin{array}{l}8.03 \pm 1 . \\
26\end{array}$ & $\begin{array}{l}8.96 \pm 1 . \\
01\end{array}$ & $\begin{array}{l}13.11 \pm 1 . \\
30\end{array}$ & $\begin{array}{l}11.14 \pm 0 \text {. } \\
97\end{array}$ & $\begin{array}{l}9.07 \pm 0 . \\
83\end{array}$ \\
\hline
\end{tabular}

$\mathrm{N}=3 ; \pm \mathrm{SD}$

Table 4: In vitro residence time of different GR films

\begin{tabular}{|c|c|c|c|c|c|c|c|c|c|c|c|c|}
\hline \multirow[t]{2}{*}{ Parameters } & \multicolumn{12}{|c|}{ Formulation code } \\
\hline & C1P1G2 & C1P2G2 & C1P3G2 & C2P1G2 & C2P2G2 & C2P3G2 & C3P1G2 & C3P2G2 & C3P3G2 & C1G2 & C2G2 & C3G2 \\
\hline $\begin{array}{l}\text { In vitro } \\
\text { residence } \\
\text { time (h) }\end{array}$ & $\begin{array}{l}12.52 \pm 0 \\
.36\end{array}$ & $\begin{array}{l}11.77 \pm \\
0.18\end{array}$ & $\begin{array}{l}10.93 \pm 0 . \\
51\end{array}$ & $\begin{array}{l}10.16 \pm 0 . \\
83\end{array}$ & $\begin{array}{l}9.98 \pm 0 . \\
13\end{array}$ & $\begin{array}{l}8.69 \pm 0 . \\
72\end{array}$ & $\begin{array}{l}7.88 \pm 0 . \\
25\end{array}$ & $\begin{array}{l}7.10 \pm 0 . \\
38\end{array}$ & $\begin{array}{l}6.54 \pm 0 . \\
92\end{array}$ & $\begin{array}{l}10.01 \pm 0 . \\
20\end{array}$ & $\begin{array}{l}9.24 \pm 0 . \\
12\end{array}$ & $\begin{array}{l}8.05 \pm 0 . \\
69\end{array}$ \\
\hline
\end{tabular}

$\mathrm{N}=3 ; \pm \mathrm{SD}$

Table 5: Drugs content uniformity of different GR films

\begin{tabular}{|c|c|c|c|c|}
\hline S. No. & Formulation code & \%Amoxicillin trihydrate & \%Metronidazole & \% Famotidine \\
\hline 1 & C1P1 G2 & $84.04 \pm 2.67$ & $88.93 \pm 3.44$ & $89.51 \pm 2.63$ \\
\hline 2 & C1P2 G2 & $89.72 \pm 1.83$ & $91.46 \pm 3.81$ & $87.91 \pm 1.32$ \\
\hline 3 & C1P3 G2 & $92.38 \pm 3.41$ & $85.33 \pm 2.57$ & $86.34 \pm 1.85$ \\
\hline 4 & C2P1 G2 & $86.14 \pm 3.73$ & $82.70 \pm 3.65$ & $90.89 \pm 3.02$ \\
\hline 5 & C2P2 G2 & $83.55 \pm 2.51$ & $89.29 \pm 3.97$ & $84.22 \pm 2.18$ \\
\hline 6 & C2P3 G2 & $91.02 \pm 3.29$ & $85.56 \pm 2.85$ & $85.87 \pm 1.43$ \\
\hline 7 & C3P1 G2 & $82.25 \pm 2.83$ & $80.41 \pm 1.97$ & $87.20 \pm 1.02$ \\
\hline 8 & C3P2 G2 & $88.61 \pm 3.79$ & $83.82 \pm 2.06$ & $86.59 \pm 1.49$ \\
\hline 9 & C3P3 G2 & $85.12 \pm 3.18$ & $86.47 \pm 3.78$ & $89.62 \pm 2.57$ \\
\hline 10 & $\mathrm{C} 1 \mathrm{G} 2$ & $90.47 \pm 4.21$ & $84.76 \pm 2.64$ & $91.08 \pm 3.74$ \\
\hline 11 & $\mathrm{C} 2 \mathrm{G} 2$ & $87.18 \pm 3.93$ & $87.10 \pm 3.37$ & $83.73 \pm 2.79$ \\
\hline 12 & C3G2 & $85.51 \pm 3.52$ & $82.37 \pm 2.6$ & $88.16 \pm 2.37$ \\
\hline
\end{tabular}

$\mathrm{N}=3$; \pm SD, Drugs content was found to be in the range of $82.25 \pm 2.83$ to $92.38 \pm 3.41 \%$ of amoxicillin trihydrate, $80.41 \pm 1.97 \%$ to $91.46 \pm 3.81 \%$ metronidazole and $82.91 \pm 1.31 \%$ to $91.08 \pm 3.74 \%$ of famotidine for formulation C1P1G2 to C3G2.

Table 6: \% Cumulative release profile of amoxicillin trihydrate from different GR films

\begin{tabular}{|c|c|c|c|c|c|c|c|c|c|c|c|c|}
\hline \multirow{2}{*}{$\begin{array}{l}\text { Time } \\
\text { (h) }\end{array}$} & \multicolumn{12}{|c|}{ \% Cumulative release of amoxicillin trihydrate } \\
\hline & C1P1G2 & C1P2G2 & C1P3G2 & C2P1G2 & C2P2G2 & C2P3G2 & C3P1G2 & C3P2G2 & C3P3 G2 & C1G2 & C2G2 & C3G2 \\
\hline \multirow[t]{2}{*}{1} & $19.41 \pm 0.9$ & $22.18 \pm 0$ & $12.86 \pm 1$ & $6.16 \pm 1.4$ & $11.78 \pm 1$ & $5.18 \pm 1$. & $1.9 \pm 1.7$ & $3.16 \pm 1$ & $0.79 \pm 1.0$ & $8.57 \pm$ & $5.12 \pm 1$ & $1.21 \pm$ \\
\hline & 8 & .75 & .20 & 4 & .32 & 91 & 9 & 55 & 1 & 0.72 & .68 & 2.97 \\
\hline \multirow[t]{2}{*}{2} & $27.72 \pm 1.0$ & $31.08 \pm 1$ & $19.31 \pm 1$ & $12.72 \pm 1$ & $18.42 \pm 1$ & $11.57 \pm 1$ & $4.24 \pm 2$. & $7.49 \pm 1$. & $2.72 \pm 1.9$ & 15.36 & $8.78 \pm 3$ & $3.92 \pm$ \\
\hline & 2 & .72 & .99 & 08 & .72 & .42 & 05 & 59 & 0 & \pm 1.29 & .17 & 1.44 \\
\hline \multirow[t]{2}{*}{3} & $36.22 \pm 1.5$ & $40.29 \pm 1$ & $27.69 \pm 2$ & $19.91 \pm 1$ & $31.11 \pm 1$ & $19.50 \pm 1$ & $8.39 \pm 2$. & $13.54 \pm 2$ & $5.21 \pm 2.3$ & 22.31 & $13.42 \pm$ & $9.86 \pm$ \\
\hline & 8 & .77 & .83 & 31 & .07 & .70 & 71 & .00 & 8 & \pm 1.13 & 2.06 & 0.81 \\
\hline \multirow[t]{2}{*}{4} & $45.19 \pm 0.1$ & $45.13 \pm 2$ & $37.25 \pm 0$ & $33.08 \pm 1$. & $40.02 \pm 1$ & $28.32 \pm 1$ & $15.26 \pm 1$ & $24.29 \pm 1$ & $8.50 \pm 0.8$ & 33.67 & $19.11 \pm$ & 18.63 \\
\hline & 1 & .11 & .66 & 07 & .93 & .49 & .84 & .57 & 1 & \pm 1.76 & 0.51 & \pm 1.62 \\
\hline \multirow[t]{2}{*}{5} & $54.44 \pm 1.0$ & $50.74 \pm 1$ & $46.55 \pm 1$ & $40.23 \pm 1$ & $47.29 \pm 1$ & $37.10 \pm 1$ & $19.80 \pm 1$ & $32.07 \pm 1$ & $11.23 \pm 0$ & 41.36 & $26.02 \pm$ & 26.12 \\
\hline & 3 & .48 & .03 & 66 & .38 & .22 & .27 & .12 & 39 & \pm 1.28 & 1.02 & \pm 0.71 \\
\hline \multirow[t]{2}{*}{6} & $63.38 \pm 0.8$ & $68.52 \pm 2$ & $54.24 \pm 0$ & $49.51 \pm 2$ & $55.4 \pm 2$ & $43.05 \pm 2$ & $23.14 \pm 1$ & $38.1 \pm 0$ & $16.19 \pm 2$. & 50.48 & $32.41 \pm$ & 33.02 \\
\hline & 8 & .05 & .52 & 48 & 03 & .07 & .92 & 83 & 60 & \pm 2.68 & 1.54 & \pm 0.45 \\
\hline \multirow[t]{2}{*}{7} & $74.06 \pm 1.3$ & $79.17 \pm 0$ & $64.08 \pm 2$ & $58.21 \pm 2$. & $63.07 \pm 1$ & 51.19 & $26.07 \pm$ & $42.36 \pm$ & $20.57 \pm$ & 57.11 & 41.29士 & 37.46 \\
\hline & 7 & .41 & .93 & 01 & .08 & 1.77 & 0.28 & 1.46 & 1.29 & \pm 2.67 & 2.41 & \pm 0.81 \\
\hline \multirow[t]{2}{*}{8} & $83.77 \pm 2.4$ & $87.91 \pm 1$ & $70.32 \pm 3$ & $67.02 \pm 1$ & $71.63 \pm 2$ & $60.71 \pm$ & $31.63 \pm$ & $50.91 \pm$ & $24.98 \pm$ & 67.29 & $50.02 \pm$ & 42.59 \\
\hline & 4 & .83 & .58 & 89 & .34 & 2.15 & 1.24 & 1.39 & 0.67 & \pm 2.93 & 0.37 & \pm 3.06 \\
\hline
\end{tabular}


Table 7: In vitro release profile of metronidazole from different GR films

\begin{tabular}{|c|c|c|c|c|c|c|c|c|c|c|c|c|}
\hline \multirow{2}{*}{$\begin{array}{l}\text { Ti } \\
\text { me } \\
\text { (h) }\end{array}$} & \multicolumn{12}{|c|}{ \% Cumulative release of metronidazole } \\
\hline & C1P1G2 & C1P2G2 & C1P3G2 & C2P1G2 & C2P2G2 & C2P3G2 & C3P1G2 & C3P2G2 & C3P3G2 & C1G2 & C2G2 & C3G2 \\
\hline \multirow[t]{2}{*}{1} & $24.70 \pm 1$ & $29.03 \pm 1$ & $15.52 \pm 1$ & $9.37 \pm 0.2$ & $17.56 \pm 1$. & $5.01 \pm 0.2$ & $3.99 \pm 0.6$ & $3.81 \pm 0.4$ & $0.51 \pm 0.1$ & $9.63 \pm 0.7$ & $4.48 \pm 1.2$ & $3.36 \pm 0.8$ \\
\hline & 53 & 43 & 72 & 9 & 32 & 4 & 8 & 8 & 3 & 1 & 2 & 1 \\
\hline \multirow[t]{2}{*}{2} & $33.81 \pm 1$. & $36.67 \pm 1$. & $25.20 \pm 1$ & $18.03 \pm 0$. & $25.13 \pm 2$. & $11.77 \pm 1$. & $9.59 \pm 0.8$ & $8.27 \pm 0.2$ & $2.03 \pm 0.8$ & $19.15 \pm 1$. & $10.37 \pm 0$ & $7.19 \pm 1.0$ \\
\hline & 72 & 66 & 46 & 79 & 09 & 55 & 3 & 3 & 5 & 90 & 14 & 7 \\
\hline \multirow[t]{2}{*}{3} & $41.04 \pm 1$ & $45.18 \pm 2$ & $39.01 \pm 2$. & $25.66 \pm 1$. & $34.28 \pm 1$ & $23.38 \pm 3$ & $14.11 \pm 2$ & $14.19 \pm 0$. & $4.96 \pm 1.0$ & $26.39 \pm 2$. & $16.85 \pm 1$ & $12.10 \pm 2$ \\
\hline & 29 & 53 & 29 & 90 & 95 & 63 & 84 & 39 & 2 & 65 & 78 & 41 \\
\hline \multirow[t]{2}{*}{4} & $50.29 \pm 2$ & $54.41 \pm 2$ & $48.32 \pm 1$ & $34.18 \pm 2$. & $43.73 \pm 2$ & $31.45 \pm 2$. & $21.43 \pm 1$ & $25.02 \pm 1$ & $7.15 \pm 0.2$ & $34.45 \pm 1$. & $26.15 \pm 1$. & $18.32 \pm 1$ \\
\hline & 92 & 10 & 01 & 81 & 68 & 44 & 38 & 66 & 3 & 90 & 62 & 03 \\
\hline \multirow[t]{2}{*}{5} & $63.21 \pm 3$ & $69.29 \pm 3$ & $55.16 \pm 2$ & $42.39 \pm 3$ & $52.36 \pm 3$ & $39.20 \pm 1$ & $28.07 \pm 3$ & $30.37 \pm 2$. & $10.39 \pm 1$ & $42.99 \pm 1$. & $31.76 \pm 0$ & $23.05 \pm 2$ \\
\hline & 15 & 84 & 74 & 31 & 91 & 83 & 52 & 50 & 77 & 24 & 98 & 33 \\
\hline \multirow[t]{2}{*}{6} & $72.56 \pm 3$ & $76.11 \pm 1$. & $63.81 \pm 2$. & $54.70 \pm 2$. & $61.09 \pm 2$ & $44.04 \pm 3$ & $32.52 \pm 2$ & $40.12 \pm 3$ & $15.73 \pm 1$ & $55.24 \pm 0$ & $39.21 \pm 2$. & $30.47 \pm 2$ \\
\hline & 88 & 72 & 02 & 07 & 47 & 19 & 65 & 05 & 23 & 96 & 11 & 15 \\
\hline \multirow[t]{2}{*}{7} & $81.18 \pm 2$. & $87.78 \pm 1$ & $70.22 \pm 1$ & $61.04 \pm 1$ & $72.61 \pm 3$ & $52.61 \pm 2$ & $38.79 \pm 1$ & $46.20 \pm 2$ & $19.55 \pm 0$ & $62.31 \pm 2$ & $47.81 \pm 1$ & $37.63 \pm 2$ \\
\hline & 01 & 46 & 66 & 99 & 34 & 91 & 82 & 83 & 70 & 13 & 32 & 10 \\
\hline \multirow[t]{2}{*}{8} & $90.51 \pm 2$ & $96.09 \pm 3$ & $77.19 \pm 0$. & $69.28 \pm 3$ & $81.92 \pm 3$ & $59.22 \pm 2$ & $42.20 \pm 3$ & $51.07 \pm 3$ & $24.06 \pm 1$ & $69.57 \pm 2$ & $51.63 \pm 1$ & $42.18 \pm 3$ \\
\hline & 52 & 70 & 97 & 60 & 18 & 71 & 44 & 01 & 04 & 77 & 90 & 28 \\
\hline
\end{tabular}

$\mathrm{N}=3 ; \pm \mathrm{SD}$

Table 8: In vitro release profile of famotidine from different GR films

\begin{tabular}{|c|c|c|c|c|c|c|c|c|c|c|c|c|}
\hline \multirow{2}{*}{$\begin{array}{l}\text { Tim } \\
\text { e } \\
\text { (h) }\end{array}$} & \multicolumn{12}{|c|}{$\%$ Cumulative release of famotidine } \\
\hline & C1P1G2 & C1P2G2 & C1P3G2 & C2P1G2 & C2P2G2 & $\begin{array}{l}\text { C2P3G } \\
2\end{array}$ & $\begin{array}{l}\text { C3P1G } \\
2\end{array}$ & $\begin{array}{l}\text { C3P2G } \\
2\end{array}$ & $\begin{array}{l}\text { C3P3G } \\
2\end{array}$ & C1G2 & C2G2 & C3G2 \\
\hline \multirow[t]{2}{*}{1} & $21.26 \pm 0.4$ & $25.6 \pm 0.2$ & $13.87 \pm 1.9$ & $8.72 \pm 0.1$ & $14.27 \pm 0.1$ & $7.59 \pm 0$. & $2.09 \pm 0$. & $8.03 \pm 0$. & $0.36 \pm 0$. & $9.52 \pm$ & $3.92 \pm$ & 2.45 \\
\hline & 5 & 7 & 2 & 9 & 7 & 66 & 09 & 56 & 15 & 0.17 & 0.32 & \pm 0.08 \\
\hline \multirow[t]{2}{*}{2} & $30.73 \pm 1.3$ & $34.1 \pm 1.4$ & $21.64 \pm 1.2$ & $16.29 \pm 1$ & $22.86 \pm 1.6$ & $14.33 \pm$ & $5.97 \pm 0$ & $13.72 \pm$ & $1.87 \pm 0$ & 17.02 & $9.26 \pm$ & $7.94 \pm$ \\
\hline & 1 & 5 & 7 & 58 & 1 & 1.45 & 27 & 0.92 & 38 & \pm 0.54 & 0.75 & 0.61 \\
\hline \multirow[t]{2}{*}{3} & $38.13 \pm 1.9$ & $43.0 \pm 1.2$ & $33.48 \pm 2.7$ & $24.52 \pm 1$. & $31.22 \pm 1.0$ & $22.02 \pm$ & $10.29 \pm$ & $24.18 \pm$ & $3.29 \pm$ & 25.29 & 19.08 & 12.05 \\
\hline & 7 & 9 & 6 & 21 & 4 & 1.01 & 1.96 & 1.49 & 2.07 & \pm 1.02 & \pm 1.12 & \pm 1.05 \\
\hline \multirow[t]{2}{*}{4} & $47.80 \pm 1.0$ & $52.2 \pm 2.6$ & $45.21 \pm 1.9$ & $33.48 \pm 2$. & $42.01 \pm 1.9$ & $31.92 \pm$ & $18.01 \pm$ & $32.16 \pm$ & $6.08 \pm$ & 32.50 & 30.19 & 19.57 \\
\hline & 8 & 8 & 0 & 56 & 0 & 2.06 & 1.94 & 2.87 & 0.82 & \pm 1.29 & \pm 0.46 & \pm 1.77 \\
\hline \multirow[t]{2}{*}{5} & $59.94 \pm 1.9$ & $65.4 \pm 2.5$ & $53.37 \pm 2.5$ & $41.11 \pm 2$. & $50.39 \pm 2.2$ & $39.86 \pm$ & $25.33 \pm$ & $40.25 \pm$ & $8.57 \pm$ & 41.31 & 38.56 & 26.18 \\
\hline & 0 & 6 & 5 & 11 & 8 & 2.79 & 1.56 & 2.56 & 1.79 & \pm 0.47 & \pm 1.39 & \pm 1.16 \\
\hline \multirow[t]{2}{*}{6} & $67.28 \pm 1.8$ & $73.3 \pm 2.0$ & $60.24 \pm 2.1$ & $50.15 \pm 2$. & $58.16 \pm 1.7$ & $47.44 \pm$ & $31.19 \pm$ & $49.56 \pm$ & $13.61 \pm$ & 49.73 & 42.91 & 30.11 \\
\hline & 3 & 9 & 2 & 46 & 0 & 1.32 & 2.87 & 2.08 & 1.06 & \pm 1.69 & \pm 2.15 & \pm 1.07 \\
\hline \multirow[t]{2}{*}{7} & $78.12 \pm 1.4$ & $84.5 \pm 2.4$ & $67.73 \pm 2.4$ & $59.26 \pm 1$ & $67.29 \pm 2.0$ & $56.73 \pm$ & $38.86 \pm$ & $56.09 \pm$ & 18.35士 & 58.19 & 49.22 & 38.83 \\
\hline & 8 & 0 & 1 & 89 & 7 & 2.97 & 2.59 & 2.31 & 1.12 & \pm 1.25 & \pm 2.01 & \pm 1.56 \\
\hline \multirow[t]{2}{*}{8} & $86.46 \pm 2.7$ & $92.1 \pm 3.0$ & $74.32 \pm 1.8$ & $67.37 \pm 2$. & $75.56 \pm 3.0$ & $65.06 \pm$ & $43.55 \pm$ & $64.89 \pm$ & $23.72 \pm$ & 67.42 & 53.67 & 42.55 \\
\hline & 8 & 7 & 9 & 90 & 8 & 2.18 & 2.79 & 3.77 & 2.62 & \pm 1.43 & \pm 2.14 & \pm 2.61 \\
\hline
\end{tabular}

$\mathrm{N}=3 ; \pm \mathrm{SD}$

The in vitro drug release from the various prepared GR films were studied using the modified diffusion cell. The release profile of the drugs from different formulations exhibits that the drugs release from these films is following non-fickian diffusion as the value of diffusional release exponent $(\eta)$ is in the range of 0.6 to 0.8 . The reason for the non-fickian diffusion of the drugs from the GR films could be due to the formation of solvent filled pore in the matrix and erosion of the polymeric matrix at $\mathrm{pH}$ 1.2.

Table 9: Kinetic release data of amoxicillin trihydrate from different GR films

\begin{tabular}{|c|c|c|c|c|}
\hline S. No. & Formulation code & $\eta$ & $\mathbf{k}$ & $\mathbf{R}^{2}$ \\
\hline 1 & C1P1 G2 & 0.666 & 17.22 & 0.9983 \\
\hline 2 & C1P2 G2 & 0.684 & 19.86 & 0.9934 \\
\hline 3 & C1P3 G2 & 0.7037 & 18.6 & 0.9924 \\
\hline 4 & C2P1 G2 & 0.6365 & 20.23 & 0.9937 \\
\hline 5 & $\mathrm{C} 2 \mathrm{P} 2 \mathrm{G} 2$ & 0.7633 & 16.95 & 0.9951 \\
\hline 6 & C2P3 G2 & 0.7821 & 21.63 & 0.9918 \\
\hline 7 & C3P1 G2 & 0.7742 & 18.41 & 0.9962 \\
\hline 8 & C3P2 G2 & 0.6591 & 19.28 & 0.9891 \\
\hline 9 & C3P3 G2 & 0.8432 & 20.47 & 0.9997 \\
\hline 10 & C1G2 & 0.6641 & 17.77 & 0.9925 \\
\hline 11 & $\mathrm{C} 2 \mathrm{G} 2$ & 0.7609 & 19.08 & 0.9885 \\
\hline 12 & C3G2 & 0.7462 & 20.73 & 0.9988 \\
\hline
\end{tabular}


Table 10: Kinetic release data of metronidazole from different GR films

\begin{tabular}{|c|c|c|c|c|}
\hline S. No. & Formulation code & $\eta$ & $\mathbf{k}$ & $\mathbf{R}^{2}$ \\
\hline 1 & C1P1 G2 & 0.767 & 20.72 & 0.9927 \\
\hline 2 & C1P2 G2 & 0.7962 & 16.66 & 0.9985 \\
\hline 3 & C1P3 G2 & 0.6454 & 18.47 & 0.9876 \\
\hline 4 & C2P1 G2 & 0.7158 & 21.04 & 0.9959 \\
\hline 5 & C2P2 G2 & 0.7462 & 18.36 & 0.9874 \\
\hline 6 & C2P3 G2 & 0.6910 & 19.75 & 0.9972 \\
\hline 7 & C3P1 G2 & 0.7721 & 20.72 & 0.9912 \\
\hline 8 & C3P2 G2 & 0.8291 & 17.17 & 0.9943 \\
\hline 9 & C3P3 G2 & 0.7104 & 19.38 & 0.9965 \\
\hline 10 & $\mathrm{C} 1 \mathrm{G} 2$ & 0.779 & 21.06 & 0.9881 \\
\hline 11 & $\mathrm{C} 2 \mathrm{G} 2$ & 0.6594 & 16.45 & 0.9913 \\
\hline 12 & $\mathrm{C} 3 \mathrm{G} 2$ & 0.7547 & 18.53 & 0.9979 \\
\hline
\end{tabular}

Table 11: Kinetic release data of famotidine from different GR films

\begin{tabular}{llll}
\hline S. No. & Formulation code & $\eta$ & $\mathbf{k}$ \\
\hline 1 & C1P1 G2 & 0.667 & 17.83 \\
2 & C1P2 G2 & 0.6912 & 19.06 \\
3 & C1P3 G2 & 0.6520 & 20.18 \\
4 & C2P1 G2 & 0.7048 & 18.52 \\
5 & C2P2 G2 & 0.7206 & 21.93 \\
6 & C2P3 G2 & 0.7519 & 0.9903 \\
7 & C3P1 G2 & 0.6771 & 0.9859 \\
8 & C3P2 G2 & 0.7391 & 0.9923 \\
9 & C3P3 G2 & 0.7156 & 0.987 \\
10 & C1G2 & 0.7783 & 0.9812 \\
11 & C2G2 & 0.7514 & 0.9987 \\
12 & C3G2 & 0.7428 & 0.9925 \\
\hline
\end{tabular}

The formulation C1P2G2 film mixture of chitosan: PAA in 2:1 ratio retards the rate and degree of erosion due to increased interaction between carboxylic group of PAA and amines of chitosan. C1P2G2 film presented a suitable controlled release profile, showed $31.63 \pm 1.24 \%$ of amoxicillin trihydrate, $42.20 \pm 3.44 \%$ of metronidazole and $35.55 \pm 2.61 \%$ of famotidine release.

These release result will ensure maximum availability of the drugs in the stomach. The greater the PAA content in the IPC, the faster the release rate of drugs was achieved; therefore the C3P1G2 film with the highest chitosan-PAA ratio $(0.5: 2.0)$ attained $87.91 \pm 1.83 \%$ of amoxicillin, $96.09 \pm 3.70 \%$ of metronidazole and $92.1 \pm 3.07 \%$ of famotidine release. This may be attributed to the fact that PAA presented a greater amount of free carboxylic pendent groups that would lead to a major expansion of the polymeric chains, increasing the rate of movement of the erosion front. The rapid swelling and drugs release demonstrated by formulation C1P2G2 might be beneficial for site-specific amoxicillin, metronidazole and famotidine delivery in the stomach, because of the limitations of the gastric emptying time.

Table 12: Ex vivo drugs permeation profile of optimized GR films formulations

\begin{tabular}{|c|c|c|c|c|c|c|}
\hline \multirow[t]{3}{*}{ Time (h) } & \multicolumn{6}{|c|}{$\%$ Cumulative drugs permeated } \\
\hline & \multicolumn{3}{|c|}{ Formulation code (C1P2G2) } & \multicolumn{3}{|c|}{ Formulation code (C1G2) } \\
\hline & Amoxicillin & Metronidazole & Famotidine & Amoxicillin & Metronidazole & Famotidine \\
\hline 1 & $0.34 \pm 0.14$ & $0.96 \pm 0.09$ & $0.51 \pm 0.20$ & $0.16 \pm 0.11$ & $0.42 \pm 0.27$ & $0.35 \pm 0.04$ \\
\hline 2 & $1.98 \pm 0.72$ & $2.72 \pm 0.53$ & $2.33 \pm 0.88$ & $1.04 \pm 0.56$ & $2.50 \pm 0.43$ & $1.66 \pm 0.27$ \\
\hline 3 & $3.67 \pm 0.36$ & $5.16 \pm 0.97$ & $4.89 \pm 1.01$ & $2.38 \pm 0.93$ & $4.92 \pm 0.71$ & $3.91 \pm 0.41$ \\
\hline 4 & $5.46 \pm 0.57$ & $8.30 \pm 0.72$ & $7.21 \pm 1.66$ & $4.65 \pm 0.72$ & $6.11 \pm 0.99$ & $5.15 \pm 0.83$ \\
\hline 5 & $7.90 \pm 0.91$ & $11.99 \pm 1.47$ & $9.54 \pm 2.31$ & $6.93 \pm 1.24$ & $9.42 \pm 1.52$ & $7.44 \pm 1.02$ \\
\hline 6 & $10.12 \pm 0.65$ & $14.48 \pm 1.82$ & $12.46 \pm 1.73$ & $8.07 \pm 1.82$ & $11.89 \pm 1.28$ & $9.92 \pm 1.67$ \\
\hline 7 & $12.53 \pm 0.49$ & $18.03 \pm 1.03$ & $15.04 \pm 2.08$ & $10.21 \pm 1.16$ & $15.25 \pm 1.69$ & $11.07 \pm 1.43$ \\
\hline 8 & $14.39 \pm 1.51$ & $20.91 \pm 2.75$ & $17.65 \pm 2.37$ & $12.10 \pm 1.59$ & $18.90 \pm 2.03$ & $14.38 \pm 1.39$ \\
\hline
\end{tabular}

$\mathrm{N}=3 ; \pm \mathrm{SD}$

Drugs permeation across the stomach mucosal membrane for C1P2G2 and C1G2 GR films was assessed and maximum drug permeation was observed with C1P2G2 films as it releases.

maximum amount of drugs while films C1G2 shown minimum drug permeation as it releases minimum amount of drugs and less bioadhesion, and low swell ability due to absence of PAA and IPC.
The mucoadhesive studies indicated that the formulation C1P2G2 films showed good mucoadhesive property, which is desirable for site-specific delivery to stomach. Formulation C1P2G2 containing chitosan and PAA in the ratio of 2:1 showed optimum adhering of film at the end of $8 \mathrm{~h}$ compared to C1G2 film formulation. 


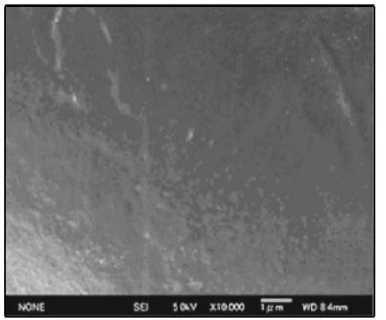

(a) $4.0 \pm 1^{\circ} \mathrm{C}$

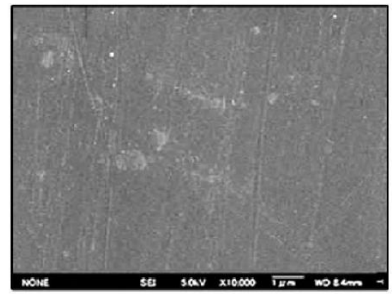

(b) $4.0 \pm 1^{\circ} \mathrm{C}$

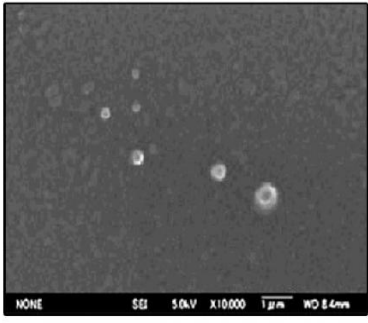

(a) $15 \pm 1^{\circ} \mathrm{C}$

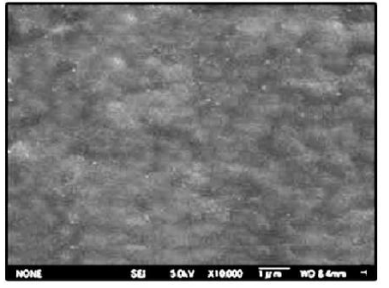

(b) $15 \pm 1^{\circ} \mathrm{C}$

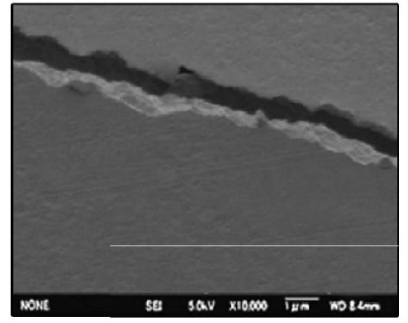

(a) $35 \pm 1^{\circ} \mathrm{C}$

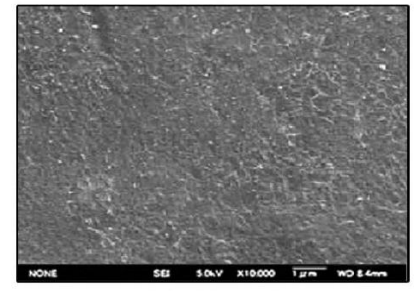

(a) $35 \pm 1^{\circ} \mathrm{C}$

Fig. 1: SEM photographs of surface of (a) fresh and (b) stored C1G2 films

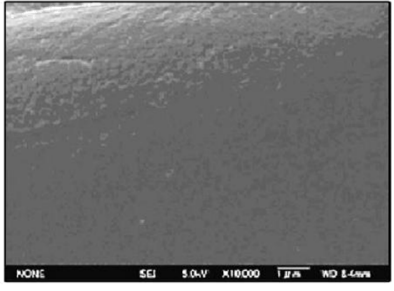

(a) $4.0 \pm 1^{\circ} \mathrm{C}$

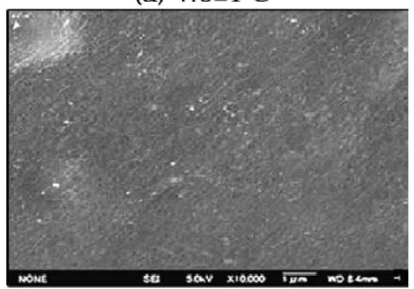

(b) $4.0 \pm 1^{\circ} \mathrm{C}$

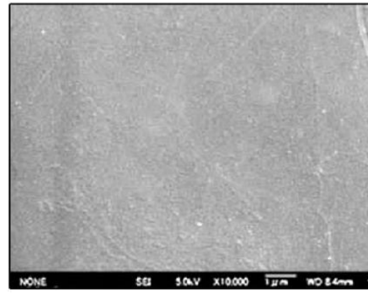

(a) $15 \pm 1^{\circ} \mathrm{C}$

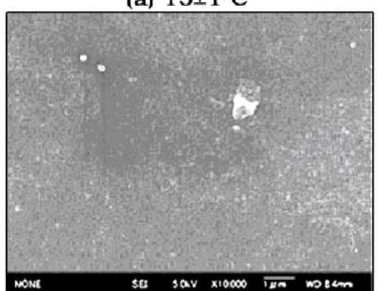

(b) $15 \pm 1^{\circ} \mathrm{C}$

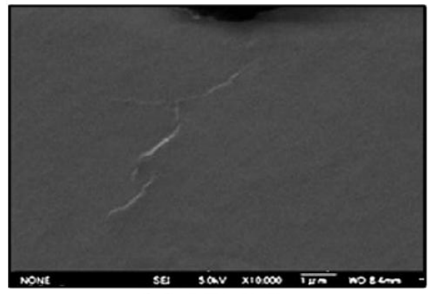

(a) $35 \pm 1^{\circ} \mathrm{C}$

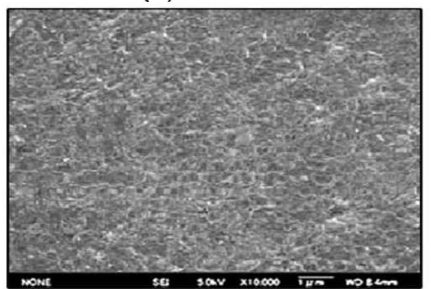

(a) $35 \pm 1^{\circ} \mathrm{C}$

Fig. 2: SEM photographs of surface of (a) fresh and (b) stored C1P2G2 films

The surface morphology of the chitosan/PAA IPC films and chitosan films were relatively having smooth surface. These results indicated that the drugs, chitosan and PAA hydrogel were mixed well in the molecular level.

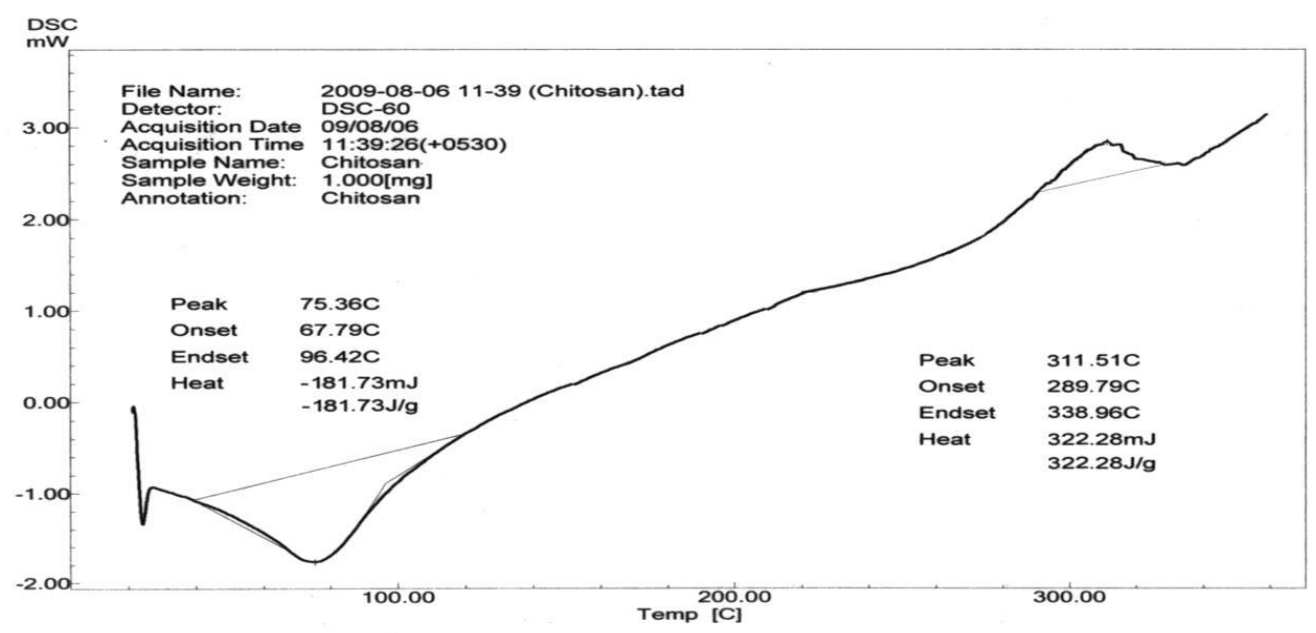

Fig. 3: DSC thermo grams of pure chitosan 


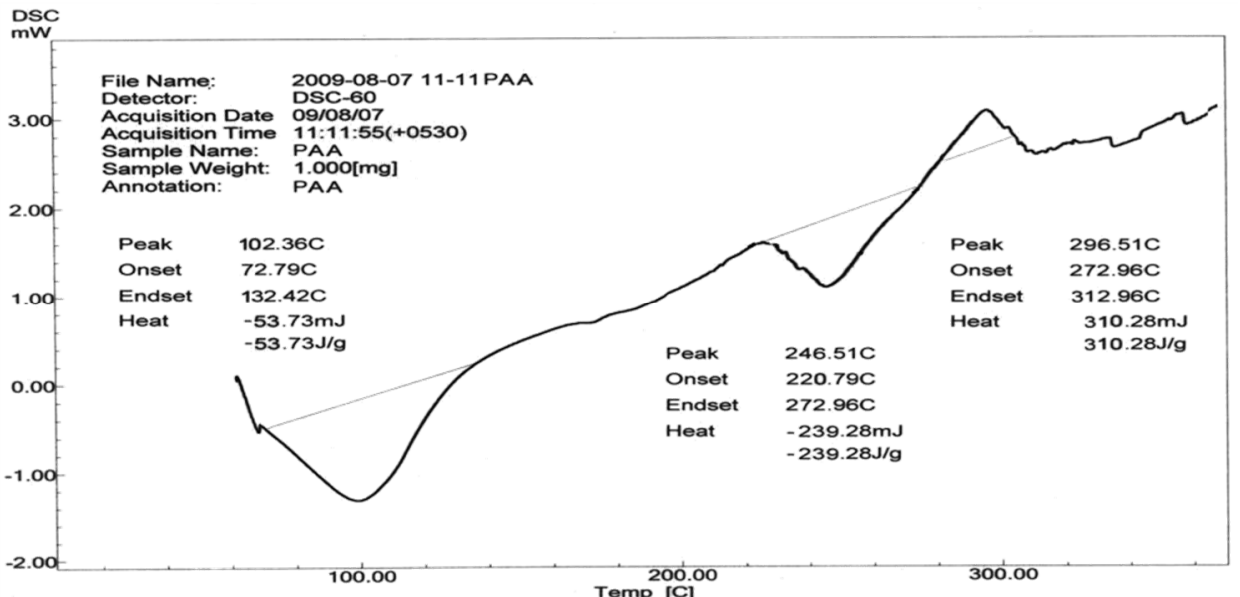

Fig. 4: DSC thermo grams of pure poly acrylic acid (PAA)

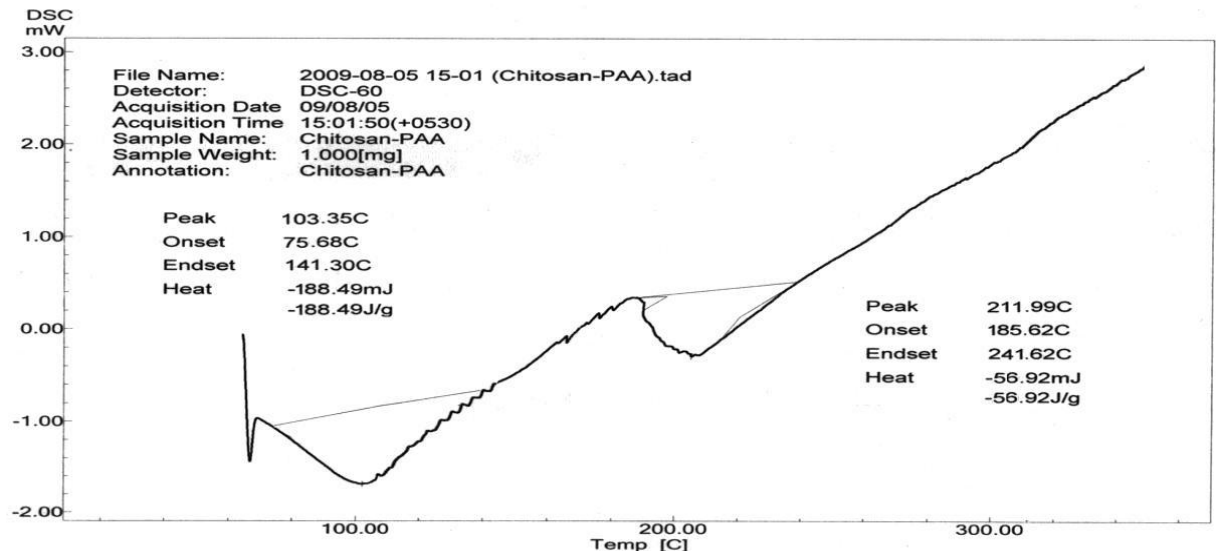

Fig. 5: DSC thermo grams of chitosan-poly acrylic acid (PAA) PIC GR film

DSC thermo gram of pure chitosan exhibits an endothermic peak at $75^{\circ} \mathrm{C}$ associated to the evaporation of absorbed water, a glass transition at 243 ${ }^{\circ} \mathrm{C}$ and an exothermic peak at about $311{ }^{\circ} \mathrm{C}$ ascribed to the polymer degradation, including saccharide ring dehydration, depolymerisation and decomposition of deacetylated and acetylated chitosan unit.

DSC thermo gram of PAA exhibits two endothermic peaks with onset temperature $102^{\circ} \mathrm{C}$ and $246^{\circ} \mathrm{C}$. The first endothermic peak has been assigned to the evaporation of water from hydrophilic groups in the polymers and the second one corresponds to a thermal degradation through intramolecular anhydride formation and water elimination.
After the second endothermic peak, the onset of a broad exothermic peak $\left(\sim 312^{\circ} \mathrm{C}\right)$ is visible in the thermo grams. It is probably related with a second degradation process involving the destruction of carboxylic groups with $\mathrm{CO}_{2}$ elimination and chain scission.

DSC thermo gram of PIC film exhibits two endothermic peaks with onset temperature $103{ }^{\circ} \mathrm{C}$ and $211^{\circ} \mathrm{C}$. The first one is associated with the vapourization of water. The second endothermic peak is probably related with the cleavage of the electrostatic interactions between the oppositely charged polymers, since it is not observed for the pure compounds.

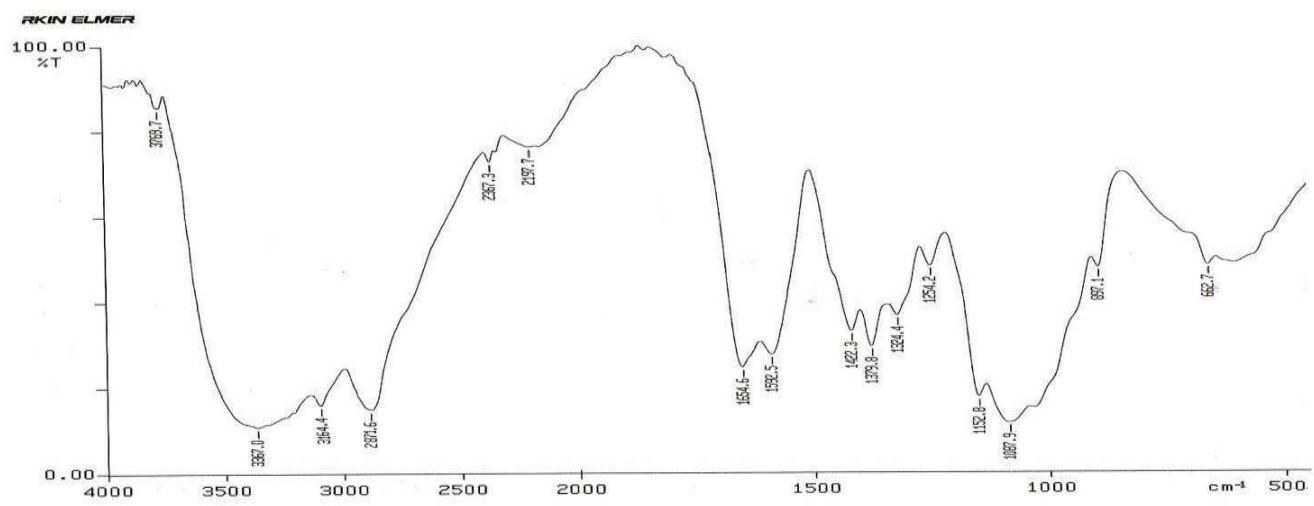

09/0?/16 12: 30 R.C. 'SAIF.P.U.CHD,
Z: 4 scans: $2.00 \mathrm{~m}-1$, flat, smooth, abex
spl.code: KP-1

Fig. 6: FTIR of chitasan GR filmfig. 


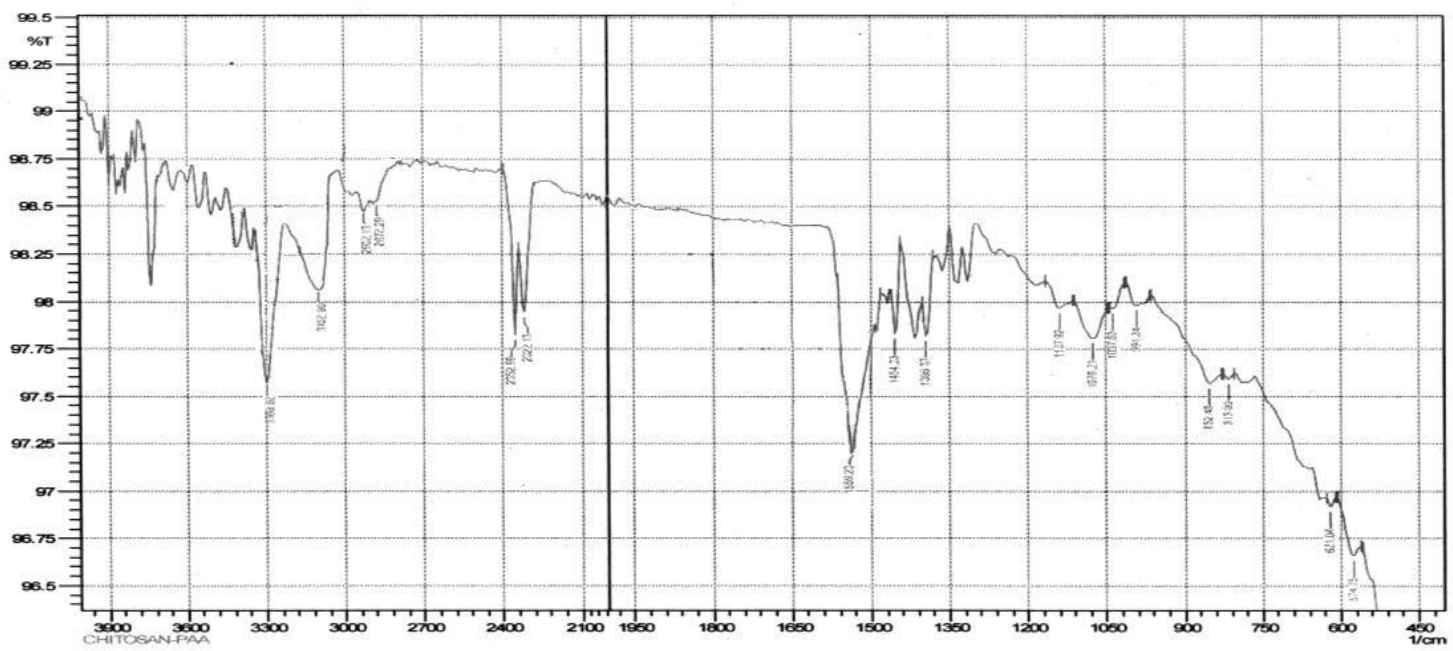

Fig. 7: FTIR of chitosan - poly acrylic acid (PAA) PIC GR film

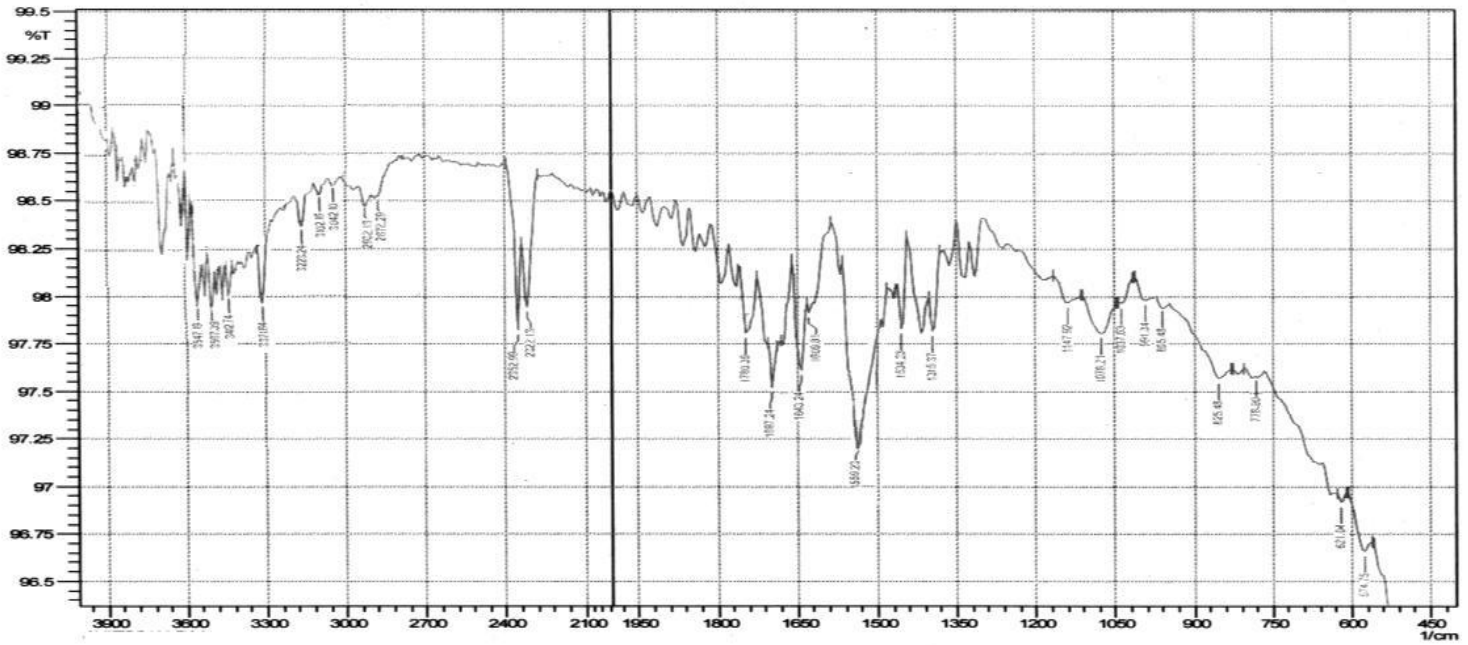

Fig. 8: FTIR of drugs loaded chitosan-poly acrylic acid (PAA) PIC GR film

From the FTIR spectra of chitosan GR film, chitosan-PAA IPC GR film and drugs loaded chitosan-PAA IPC GR film it is clear that there is no significant shift in the major peaks, which indicates that there is no interaction between the polymers and drugs used.

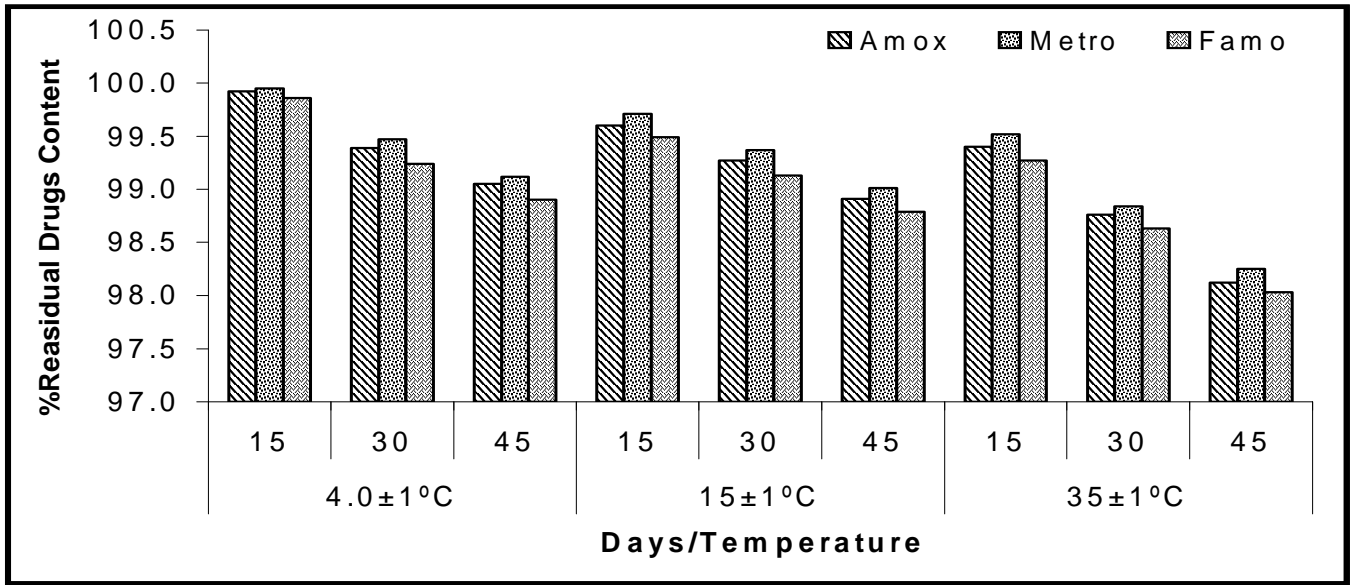

Fig. 9: Stability study data of formulation C1P2G2 film on storage at different temperature and time interval 


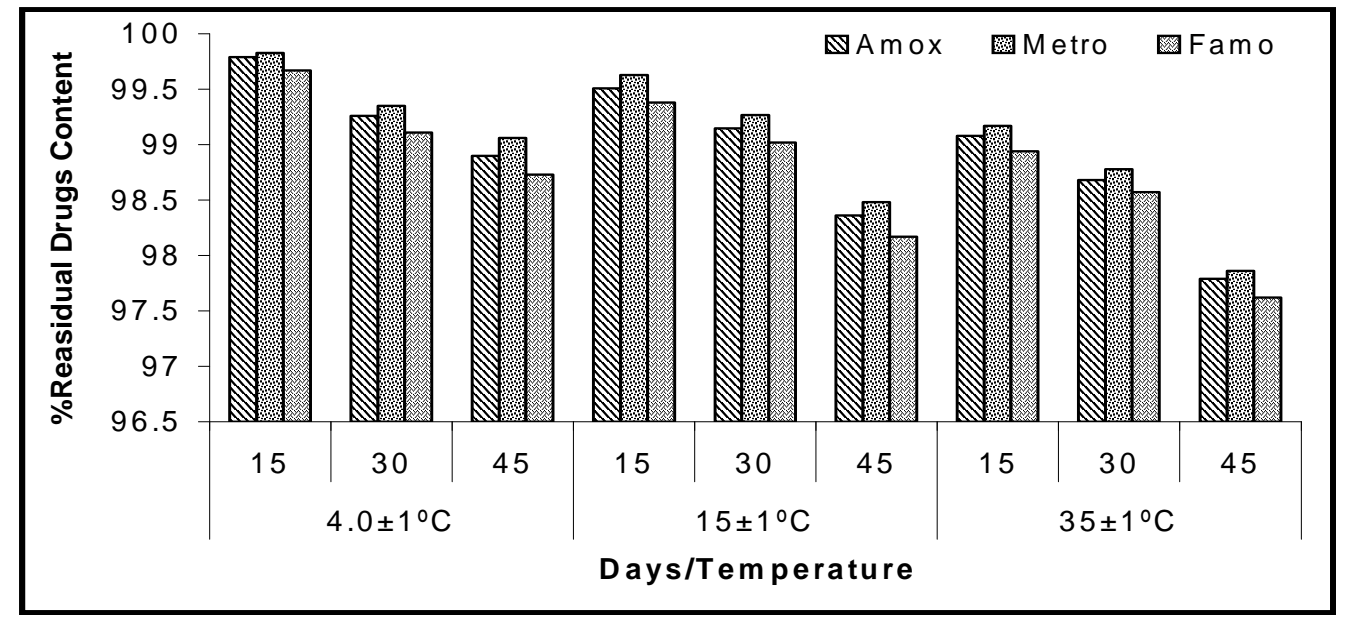

Fig. 10: Stability study data of formulation C1G2 Film on storage at different temperature and time interval

Stability of optimized formulations CH-PAA IPC (C1P2G2) and CH film (C1G2) were observed for any change in surface morphology and folding endurance. There was no significant change in the surface morphology of the films while upon storage drugs slightly lost its crystalline nature at higher temperature. Which indicates their instability at higher temperature and agglomeration of the drugs particles was observed.

There was negligible change in drugs content after storage for $45 \mathrm{~d}$ at $4.0 \pm 1^{\circ} \mathrm{C}$ and $15 \pm 1^{\circ} \mathrm{C}$, which shows that drugs are stable at $4.0- \pm 1^{\circ} \mathrm{C}$ and $15 \pm 1^{\circ} \mathrm{C}$. The residual drugs content were found to decrease at $35 \pm 1^{\circ} \mathrm{C}$. The results suggested that the formulations are stable at $4.0 \pm 1^{\circ} \mathrm{C}$.

The maximum growth inhibition for the optimized formulations $\mathrm{CH}-$ PAA IPC (C1P2G2) and CH film (C1G2) was found to be $96.77 \%$ and
92.26\%, respectively. The percent growth inhibition for the plain drugs amoxicillin, metronidazole and famotidine was found to be $51.61 \%, 46.59 \%$ and $34.76 \%$, respectively for strain in $4 \mathrm{~d}$. When drugs used in combination the $\%$ growth inhibition was found to be $81.00 \%$.

According to optical density and \% growth inhibition result, it was found that the GR films are more effective in the treatment of $H$. pylori infections taking the above-mentioned drugs as combination therapy as compared to the plain drugs. In vitro growth inhibition results show that the GR films formed are effective as a delivery system and could improve the bioavailability of the drugs in gastric acidic environment. It gives localized delivery of drugs for controlled release of drugs in upper GIT.

Table 13: To show the effect of oral free drugs solutions (Amoxicillin trihydrate $30 \mathrm{mg} / \mathrm{Kg}+\mathrm{Metronidazole} 15 \mathrm{mg} / \mathrm{Kg}+\mathrm{Famotidine} 0.45$ $\mathrm{mg} / \mathrm{Kg}$ ) and drugs loaded GR films on $\mathrm{H}$. pylori induced gastric infection in rats

\begin{tabular}{llll}
\hline S. No. & Preparations & Clearance rate (\%) & \% Bacterial recovery (Log of CFU per gastric wall) \\
\hline 1. & Control & $0(0 / 6)$ & $9.64 \pm 0.35$ \\
2. & Plain drugs solution & $33.33(2 / 6)$ & $5.83 \pm 0.23$ \\
& (Amoxicillin+Metronidazole+Famotidine) & $66.67(4 / 6)$ & $3.72 \pm 0.58$ \\
3. & Drugs loaded CH film (C1G2) & $100(6 / 6)$ & ND \\
4. & Drugs loaded CH-PAA IPC film (C1P2G2) & & \\
\hline
\end{tabular}

ND: not detected; $N=6 ; \pm S D$

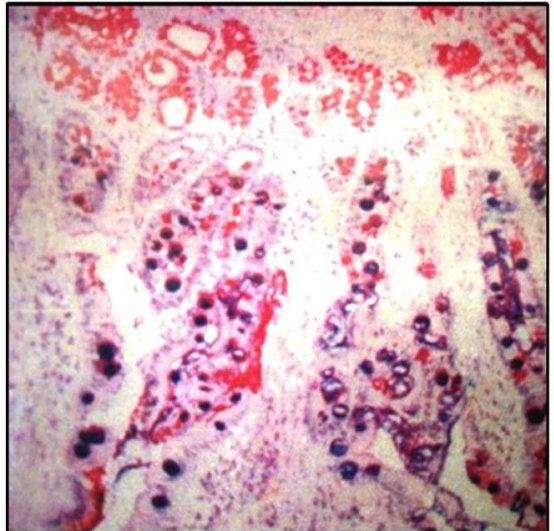

Fig. 11: Histopathological examination showing the gastric mucosa of rat suffering from moderate infection

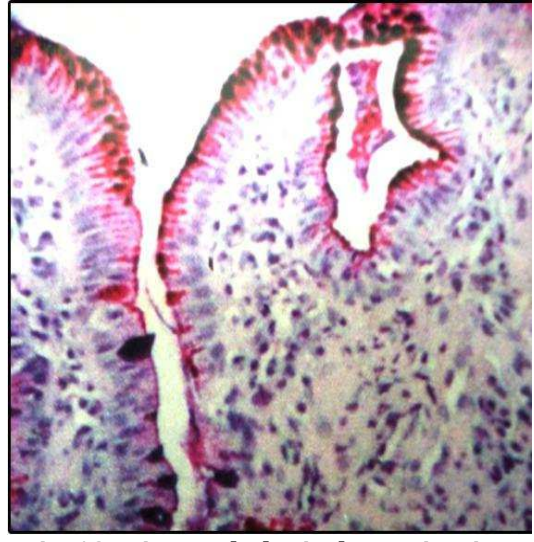

Fig. 12: Histopathological examination showing the gastric mucosa of rat suffering from mild infection

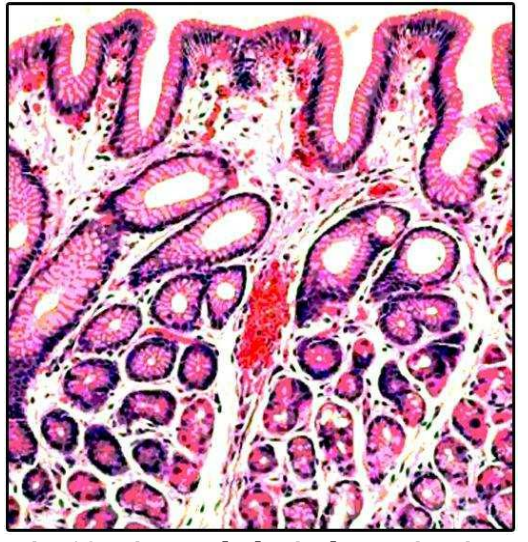

Fig. 13: Histopathological examination showing the gastric mucosa of rat free from $H$. pylori infection 
The mean bacterial count (Log CFU) for control was found to be $9.64 \pm 0.35$. After oral administration of plain drugs solution (amoxicillin, metronidazole and famotidine) it was found to be $5.83 \pm 0.23$, which is due to unavailability of $100 \%$ drugs and short residence time of drugs solution in the stomach and the low concentration of drugs reaching the $H$. pylori under the gastric mucus layer. After oral administration of drugs loaded $\mathrm{CH}$ film (C1G2) it was found to be $3.72 \pm 0.58$ and with drugs loaded CH-PAA IPC film (C1P2G2) it was not detected. The drugs loaded CH-PAA IPC film (C1P2G2) formulation exhibited better clearance from infection than $\mathrm{CH}$ film (C1G2) formulation and plain drugs solution at same doses. Drugs loaded CH-PAA IPC film formulation was found to be effective in the treatment of $H$. pylori infections effectively.

From the histopathological examination it is obvious that group of rats receiving plain drugs solution at dose amoxicillin trihydrate $30 \mathrm{mg} / \mathrm{Kg}$, metronidazole $15 \mathrm{mg} / \mathrm{Kg}$ and famotidine $0.45 \mathrm{mg} / \mathrm{Kg}$, showed moderate infection with a large population of $H$. pylori shown in fig. 11 . Group of rats receiving $\mathrm{CH}$ film formulation at same doses showed mild infection with a large population of $H$. pylori Shown in fig. 12 . Group of rats receiving CH-PAA IPC film formulation at same dose showed total absence of $H$. pylori infection shown in fig. 13, From the histopathological examination it is obvious that groups receiving drugs in the form of CH-PAA IPC film and $\mathrm{CH}$ film formulation at doses amoxicillin trihydrate $30 \mathrm{mg} / \mathrm{Kg}$, metronidazole $15 \mathrm{mg} / \mathrm{Kg}$ and famotidine $0.45 \mathrm{mg} / \mathrm{Kg}$ were better than the corresponding solution form at same doses, to eradicate the $H$. pylori infection.

Gastro-retentive dosage forms are also useful for local as well as sustained drug delivery for certain conditions, like $H$. pylori infection, which is the cause of peptic ulcers. This dosage form improves bioavailability, therapeutic efficacy and may even also allow a possible reduction in the dose because of steady therapeutic levels of drug [18-20]. Mucoadhesive polymeric films are made from chitosan (mucoadhesive) polymer adhere on the surface of gastric epithelial cells and thus it covers the ulcerative part. Protection from acidic environment due to mucoadhesive polymer increases the healing property and makes the carrier site specific thus better therapeutic index is maintained [21]. The present treatment of $H$. pylori infection is based on the combination of amoxicillin trihydrate, metronidazole and famotidine together. Triple therapy usually gives better $H$. pylori eradication than single and dual drug therapy. The presence of three drugs in the same system leads to improved efficacy of the system.

\section{CONCLUSION}

The mucoadhesive gastroretentive films of amoxicillin trihydrate, metronidazole and famotidine were developed using solvent casting method and showed a high percentage of mucoadhesion, drug entrapment efficiency, and exhibited a sustained release property. The effect of drug-to-polymer-to-polymer ratio, emulsifying agent and stirring speed significantly influence on drug entrapment and particle size. This study confirmed the mucoadherent potential of the CH-PAA IPC film. This leads to more absorption of drugs. This clearly indicates that the developed system were well taken up and processed by the cells of gastric mucosa of stomach. This shows that the system could attach the mucosal gel layer where $H$. pylori reside to effectively combat the H. pylori bacteria. Drug loaded CH-PAA IPC film formulation provided 2 times and 3 times greater anti- $H$. pylori activity than $\mathrm{CH}$ film formulation and plain drugs solution, respectively due to their bioadhesive nature and increased residence time in the stomach.

\section{AUTHORS CONTRIBUTIONS}

All the author have contributed equally

\section{CONFLICT OF INTERESTS}

Declared none

\section{REFERENCES}

1. Zhao S, Lv Y, Zhang JB, Wang B, Lv GJ, Ma XJ. Gastroretentive drug delivery systems for the treatment of Helicobacter pylori. World J Gastroenterol 2014;20:9321-9.

2. Umamaheshwari RB, Jain S, Jain NK. A new approach in gastroretentive drug delivery system using cholestyramine. Drug Delivery 2003;10:151-60.

3. Shah S, Qaqish R, Patel V, Amiji M. Evaluation of the factors influencing stomach-specific delivery of antibacterial agents for Helicobacter pylori infection. J Pharm Pharmacol 1999;51:66772.

4. Nagahara N, Akiyama Y, Nakao M, Tada M, Kitano M, Ogawa Y. Mucoadhesive microspheres containing amoxicillin for clearance of helicobacter pylori. Antimicrob Agents Chemother 1998;42:2492-4.

5. Pawar VK, Kansal S, Garg G, Awasthi R, Singodia D, Kulkarni GT. Gastroretentive dosage forms: a review with special emphasis on floating drug delivery systems. Drug Delivery 2011;18:97110 .

6. Hwang SJ, Park H, Park K. Gastric retentive drug-delivery systems. Crit Rev Ther Drug Carrier Syst 1998;15:243-84.

7. Wang H, Li W, Lu Y, Wang Z. Studies on chitosan and poly (acrylic acid) interpolymer complex. I. Preparation, structure, $\mathrm{pH}$ sensitivity, and salt sensitivity of complex-forming poly (acrylic acid): chitosan semi-interpenetrating polymer network. J Appl Poly Sci 1997;65:1445-50.

8. Khanna R, Agrawal SP, Ahuja A. Preparation and evaluation of mucoadhesive buccal films of clotrimazole for oral candida infections. Indian J Pharm Sci 1997;59:299-6.

9. Klausner EA, Lavy E, Friedman M, Hoffman A. Expandable gastroretentive dosage forms. J Controlled Release 2003;90:143-62.

10. Peppas NA. Analysis of fickian and non-fickian drug release from polymers. Pharm Acta Helvet 1985;60:110-1.

11. Shukla AK, Bishnoi RS, Kumar M, Jain CP. Development of natural and modified gum based sustained-release film-coated tablets containing poorly water-soluble drug. Asian J Pharm Clin Res 2019;12:266-27.

12. Kumar M, Shukla AK, Bishnoi RS, Jain CP. Development of UVspectrophotometric method for the determination of benidipine hydrochloride by using quality by design (QBD) approach. Int J Appl Pharm 2018;10:92-5.

13. Umamaheshwari RB, Ramteke S, Jain NK. Anti-Helicobacter pylori effect of mucoadhesive nanoparticles bearing amoxicillin in experimental gerbils model. AAPS PharmSciTech 2004;5:1-9.

14. Chin YW. Novel drug delivery systems. EdN. $2^{\text {nd }}$ Vol. 50. Revised and Expanded Marcel Dekker; 2005. p. 140-55.

15. Gennaro RA Remington. The Science and Practice of pharmacy. 20th Edn. Vol. I; 2006. p. 903-13.

16. Vasir JK, Tambwekar K, Garg S. Bioadhesive microspheres as a controlled drug delivery system. Int J Pharm 2003;255:13-32.

17. Huang Y, Leobandung W, Foss A, Peppas NA. Molecular aspects of muco-and bioadhesion: tethered structures and site-specific surfaces. J Controlled Release 2000;65:63-71.

18. Park K, Robinson JR. Bioadhesive polymers as platforms for oral-controlled drug delivery-method to study bioadhesion. Int J Pharm 1984;19:107-27.

19. Rajak P, Bhattacharya A, Sharma N, Kataki MS, Rajkumari A. Gastro-retentive floating drug delivery system-An approach in gastroretentive drug delivery. Int J Pharm Pharm Sci 2011;3:916.

20. Thomas LM. Formulation and evaluation of floating oral in-situ gel of metronidazole. Int J Pharm Pharm Sci 2014;6:265-9.

21. Elbehairy DM, Osman R, Sammour O. Inhaled taste masked spray dried ketotifen microparticles: formulation, characterization and in vitro pulmonary deposition. Int J Pharm Pharm Sci 2016;6:266-74. 